\title{
Biomedical Effects of Popular Phytonutrients and Their Phyto- chemicals: A Comprehensive Review
}

\author{
Yamixa Delgado 1,*, Céline Cassé ${ }^{2}$, Yancy Ferrer-Acosta ${ }^{3}$, Ivette J. Suárez-Arroyo ${ }^{3}$, José Rodríguez-Zayas ${ }^{1}$, Anama- \\ ris Torres ${ }^{4}$, Zally Torres-Martínez ${ }^{4}$, Daraishka Pérez ${ }^{1}$, Michael González ${ }^{5}$, Ricardo A. Velázquez-Aponte ${ }^{2}$, Josué \\ Andino 1, Clarissa Correa-Rodríguez ${ }^{1}$, Jean C. Franco ${ }^{1}$, Wandaliz Milán 1, Gabriela Rosario ${ }^{1}$, Eddian Velázquez ${ }^{1}$, \\ Jaisy Vega ${ }^{1}$, Janmary Colón ${ }^{6}$ and Christopher Batista ${ }^{7}$
}

1 San Juan Bautista School of Medicine, Urb. Turabo Gardens PR-172 Caguas, Puerto Rico, USA 00726; ydelgado@sanjuanbautista.edu (Y.D.); joserodriguez@sanjuanbautista.edu (J.R.Z.), daraishkapc@sanjuanbautista.edu (D.P.); josueav@sanjuanbautista.edu (J.A.); clarissacr@sanjuanbautista.edu (C.C.R.); jeanfm@sanjuanbautista.edu (J.C.F.); wandalizma@sanjuanbautista.edu (W.M.); gabrielarr@sanjuanbautista.edu (G.R.); eddianva@sanjuanbautista.edu (E.V); jaisyvo@sanjuanbautista.edu (J.V.)

2 Chemistry Department, University of Puerto Rico-Mayagüez Campus, PR-108, Mayagüez, Puerto Rico, USA 00682; celine.casse@upr.edu (C.C.); ricardo.velazquez5@upr.edu (R.A.V.A.)

3 Universidad Central del Caribe, School of Medicine, Ave. Laurel 100, Sta. Juanita, Bayamón, Puerto Rico, USA 00960; yancy.ferrer@uccaribe.edu (Y.R.A.); ivette.suarez@uccaribe.edu (I.J.S.A.)

4 University of Puerto Rico-Rio Piedras Campus, Av. Universidad Ste. 1401, San Juan, Puerto Rico, USA 00925; anamaris.torres@upr.edu (A.T.); zallytorres@gmail.com (Z.T.M.)

5 University of Puerto Rico-Medical Sciences Campus, Paseo Dr. José Celso Barbosa, San Juan, Puerto Rico, USA 00921; michael.gonzalez5@upr.edu

6 Universidad Ana G. Méndez-Gurabo Campus, Carr. \# 189 Km 3.3. Gurabo, Puerto Rico USA 00778; janmarycolonn@gmail.com

7 University of Puerto Rico-Bayamón Campus, Industrial Minillas 170, 63, PR-174, Bayamón, Puerto Rico, USA 00959; christopher.batista@upr.edu

* Correspondence: ydelgado@sanjuanbautista.edu; Tel.: (1+787-743-3038 X. 3220)

Featured Application: This review is significant to the researchers using plant-derived products as therapeutics. It evaluates and summarizes the most recent studies published in the last 20 years and combines the latest botanical description, pharmacological, and biomedical effects of the most popular phytonutrients and their active phytochemicals. Furthermore, this review provides the reading audience fast, summarized information of $>250$ scientific articles on the most utilized phytonutrients worldwide, of which much tertiary literature is found without the support of robust, reproducible scientific data.

\begin{abstract}
Phytonutrients are plant foods that contain many natural bioactive compounds, called phytochemicals, which expose specific biological activities. These phytonutrients and their phytochemicals may play an important role in health care maintaining normal organism functions (as preventives) and fighting against diseases (as therapeutics). Phytonutrient's components are the primary metabolites (i.e., proteins, carbohydrates, and lipids) and phytochemicals or secondary metabolites (i.e., phenolics, alkaloids, organosulfides, and terpenes). For years, several phytonutrients and their phytochemicals have demonstrated specific pharmacological and therapeutic effects in human health such as anticancer, antioxidant, antiviral, anti-inflammatory, antibacterial, antifungal, and immune response. This review summarizes the effects of the most studied or the most popular phytonutrients (i.e., turmeric, garlic, cinnamon, graviola, and oregano), and any contraindication found. This article also calculated the physicochemical properties of the main phytochemicals in the selected phytonutrients using Lipinski's, Veber's and Ghose's rules. Based on our revisions for this article, all these phytonutrients have consistently shown several in vitro, in vivo, and clinical studies with great potential as preventives and therapeutics on many diseases.
\end{abstract}

Keywords: phytonutrients; phytochemicals; turmeric; garlic; cinnamon; graviola; oregano; Lipinski's Rule of 5; Veber's Rules; Ghose Filter. 


\section{Introduction}

For centuries, plants have been considered a significant source of medicinal nutrients and compounds. Historical findings have reported the use of plants by our ancestors to treat numerous diseases [1-3]. Consequently, it has been a quest for many individuals to search for herbal supplements and natural therapies to attend to their healthcare needs, prevent diseases, and support their nutrition. Plants produce a large variety of metabolites. Primary metabolites (i.e., innate proteins, lipids, and carbohydrates) are directly involved in the main intrinsic metabolisms as normal growth, development, and reproduction of organisms. In contrast, secondary metabolites, also known as phytochemicals, confers a selective advantage to the plant organism, despite not being involved in their main metabolic pathways [4]. These phytochemicals are classified into four main chemical groups: phenolics, alkaloids, organosulfides, and terpenes [5]. Phenolics are the biggest group subdivided into seven groups: curcuminoid, stilbenes, tannins, flavonoids, phenolics acids, lignans, and coumarins [6]. A summary of the phytonutrients' metabolite composition is shown in Figure 1.

Based on this definition of secondary metabolites, phytonutrients can be considered as a whole-plant extract containing one or more phytochemicals. Since one of the functions of such secondary metabolites is to protect the plant organism from pests and diseases, it is not surprising that many of them show activity against human ailments. The scientific literature contains strong evidence supporting healthy diets rich in phytonutrients as being correlated with the prevention of chronic diseases, preventive medicine being one of the most important types of health care, if not the most [7-12]. However, the ingestion of plant-derived foods, also known as "superfoods," or phytonutrients, to take advantage of its therapeutic properties is well under debate. Primarily, because of the different features affecting the looked-for properties between superfoods and extracts or phytochemicals, obtained as pure isolated compounds.

When we consume superfoods, the first feature altering their biological effect is during the food preparation, possibly inducing chemical decomposition and thermal denaturation of most metabolites, including phytochemicals [13,14]. Secondly, the different physiological barriers in the digestion process through the gastrointestinal tract determine the absorption, bioavailability, and delivery of all nutrients[15]. Multiple research groups have demonstrated the activity of the plant extract being higher when compared to the pure isolated phytochemical when orally administrated [16]. This difference is largely due to the general low bioavailability and low absorption of these isolated natural compounds, explained by their poor solubility[16-18]. To overcome this pharmacokinetic problem and study the real therapeutic potential of the pure phytochemicals, it is recommended to use other administration routes or develop improved delivery systems [19-20]. These results expose one of the most no worthy properties of the plant extracts- their synergistic interactions between the mixture of metabolites, which creates a natural micellar nanoparticle behavior [21,22].

The development of these intrinsic micelles in the extract significantly increases the successful delivery and high absorption of the phytochemical molecules [23]. On the other hand, if the phytochemical concentration in the herbal extract is extremely low, its bioactivity would be underestimated. Furthermore, the metabolites concentration, composition, and quality from batch to batch in these extracts are considerably heterogeneous [24]. These inconsistencies make extracts challenging to fulfill the high integrity and the reproducibility required to study their therapeutic activity analytically, even when people 


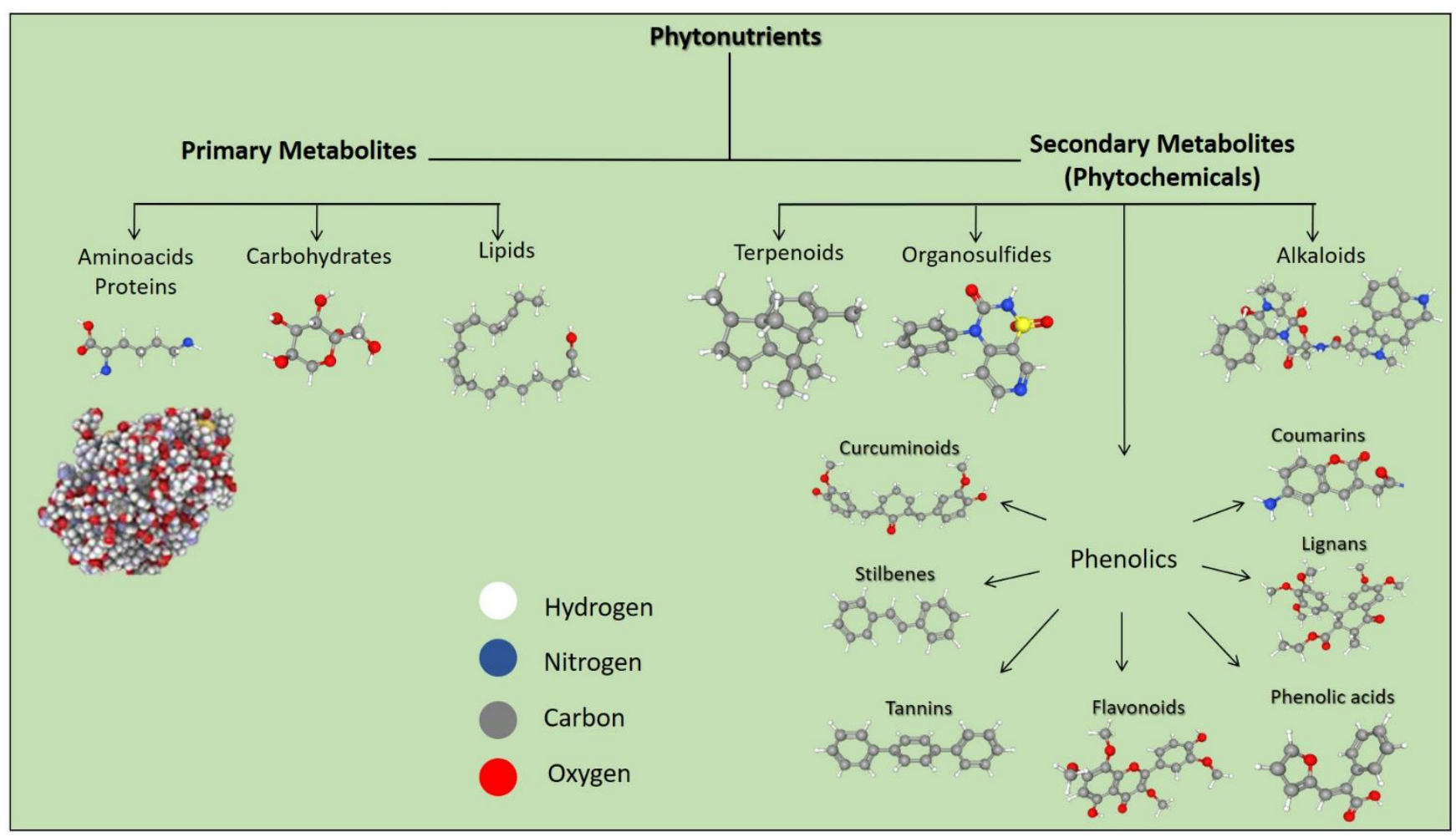

Figure 1. Phytonutrients' Composition. Plants produce primary metabolites (i.e., innate proteins, lipids, and carbohydrates) as their normal metabolic functioning and secondary metabolites (i.e., phytochemicals), primarily to protect them from predators. These phytochemicals are classified into four main chemical groups: phenolics, alkaloids, organosulfides, and terpenes. Phenolics are the biggest group subdivided into seven groups: curcuminoid, stilbenes, tannins, flavonoids, phenolics acids, lignans, and coumarins. 3D structures were visualized using PubChem [26] ball and stick model.

claim their medicinal effect [5]. Thus, for the development of new drugs, isolated active phytochemicals are preferred over crude extracts. Fortunately, basic and clinical research studies of pure phytochemicals have continued for decades and have given important therapeutic outcomes. Because of these results, almost half of the drugs available in the market are naturally derived compounds [25], showing the pertinence to our review.

Here, we aim to review studies published in the last 20 years that examine the botanical description, pharmacological, and therapeutic effect of the most popular phytonutrients, and their active phytochemicals. This review will focus on the following phytonutrients: turmeric, garlic, cinnamon, graviola, and oregano. We emphasized the biomedical areas of the anticancer, antioxidant, antiviral, anti-inflammatory, antibacterial, antifungal, and immune response presented by the mentioned phytonutrients. Besides, special attention is given to potential contraindications found while consuming these phytonutrients/phytochemicals alone or in combination with conventional medicine. After all, phytonutrients impacting the health status of individuals, in a preventive or therapeutic way, remain an attractive topic for the public looking to include food with tangible health benefits to their diets.

\section{Phytonutrients}

In the last 20 years, the researchers' interest in natural products has grown in search of alternatives for disease prevention and therapies. In this review, we looked for the health benefits of the selected phytonutrients demonstrated by scientific studies. Furthermore, we constructed Table $\mathbf{1}$ to summarize our theoretical calculations of the physicochemical properties or "drug-likeness" relevant for gastrointestinal tract absorption of the main phytochemicals in the phytonutrients: turmeric, garlic, cinnamon, graviola, and oregano. 
Table 1. Physicochemical properties calculations for the main phytochemicals of the selected phytonutrients.

$\begin{array}{cccccccccc}\text { Phytochemical } & \text { Empirical formula / } & \text { MW } & \text { HBA / } & \text { Log } & \text { Log } & \text { A } & \text { PSA } & \text { GI absorption / } \\ \text { compound name } & \text { Structure } & \text { (Da) } & \text { HBD / } & P & D & \left(\mathrm{~cm}^{3}\right) & \left(\AA^{2}\right) & \text { L-RO5, GF, and } \\ & & & \text { RB } & & & & & \text { VR violations }\end{array}$

Turmeric

\begin{tabular}{|c|c|c|c|c|c|c|c|c|}
\hline Curcumin & $\mathrm{C}_{21} \mathrm{H}_{20} \mathrm{O}_{6}$ & 368.4 & $6 / 3 / 8$ & 2.9 & 2.6 & 106 & 93.1 & High / 0 \\
\hline Demethoxycurcumin & $\mathrm{C}_{20} \mathrm{H}_{18} \mathrm{O}_{5}$ & 338.3 & $5 / 2 / 7$ & 3.2 & 2.6 & 97 & 83.8 & High / 0 \\
\hline Bisdemethoxycurcumin & $\mathrm{C}_{19} \mathrm{H}_{16} \mathrm{O}_{4}$ & 308.3 & $4 / 2 / 6$ & 3.4 & 2.8 & 91 & 74.6 & High / 0 \\
\hline$\alpha$-Turmerone & $\mathrm{C}_{15} \mathrm{H}_{22} \mathrm{O}$ & 218.3 & $1 / 0 / 4$ & 4.4 & 4.1 & 69 & 17 & High / 0 \\
\hline
\end{tabular}




\begin{tabular}{|c|c|c|c|c|c|c|c|c|}
\hline Alliin & $\mathrm{C}_{6} \mathrm{H}_{11} \mathrm{NO}_{3} \mathrm{~S}$ & 177.2 & $4 / 3 / 5$ & -0.5 & -3.3 & 44 & 99.6 & $\begin{array}{l}\text { High / } 0 \\
\text { Negative LogD }\end{array}$ \\
\hline Allicin & $\mathrm{C}_{6} \mathrm{H}_{10} \mathrm{OS}_{2}$ & 162.3 & $1 / 0 / 5$ & 1.2 & 1.4 & 46 & 61.6 & $\begin{array}{l}\text { Low / } \\
\text { TNA<20 }\end{array}$ \\
\hline Diallylsulfide & $\mathrm{C}_{6} \mathrm{H}_{10} \mathrm{~S}$ & 114.2 & $0 / 0 / 4$ & 2.6 & 2.9 & 37 & 25.3 & $\begin{array}{l}\text { Low / } \\
\text { TNA }<20 \\
\mathrm{MW}<160 \\
\mathrm{~A}<40\end{array}$ \\
\hline Z-Ajoene & $\mathrm{C}_{9} \mathrm{H}_{14} \mathrm{OS}_{3}$ & 234.4 & $1 / 0 / 8$ & 3.1 & 2.8 & 68 & 86.9 & High / 0 \\
\hline 2-Vinyl-4H-1,3-dithiin & $\mathrm{C}_{6} \mathrm{H}_{8} \mathrm{~S}_{2}$ & 144.3 & $0 / 0 / 1$ & 2.2 & 2.7 & 45 & 50.6 & $\begin{array}{l}\text { Low / } \\
\text { TNA<20 } \\
\text { MW }<160\end{array}$ \\
\hline
\end{tabular}

\section{Cinnamon}

\begin{tabular}{|c|c|c|c|c|c|c|c|c|}
\hline $\begin{array}{l}\text { (E)-Trans- } \\
\text { Cinnamaldehyde }\end{array}$ & $\mathrm{C}_{9} \mathrm{H}_{8} \mathrm{O}$ & 132.2 & $1 / 0 / 2$ & 2.1 & 1.8 & 42 & 17.1 & $\begin{array}{l}\text { Low / } \\
\text { TNA<20 } \\
\text { MW }<160\end{array}$ \\
\hline (E)-Cinnamyl Acetate & $\mathrm{C}_{11} \mathrm{H}_{12} \mathrm{O}_{2}$ & 176.2 & $2 / 0 / 4$ & 2.6 & 2.6 & 53 & 26.3 & High / 0 \\
\hline
\end{tabular}




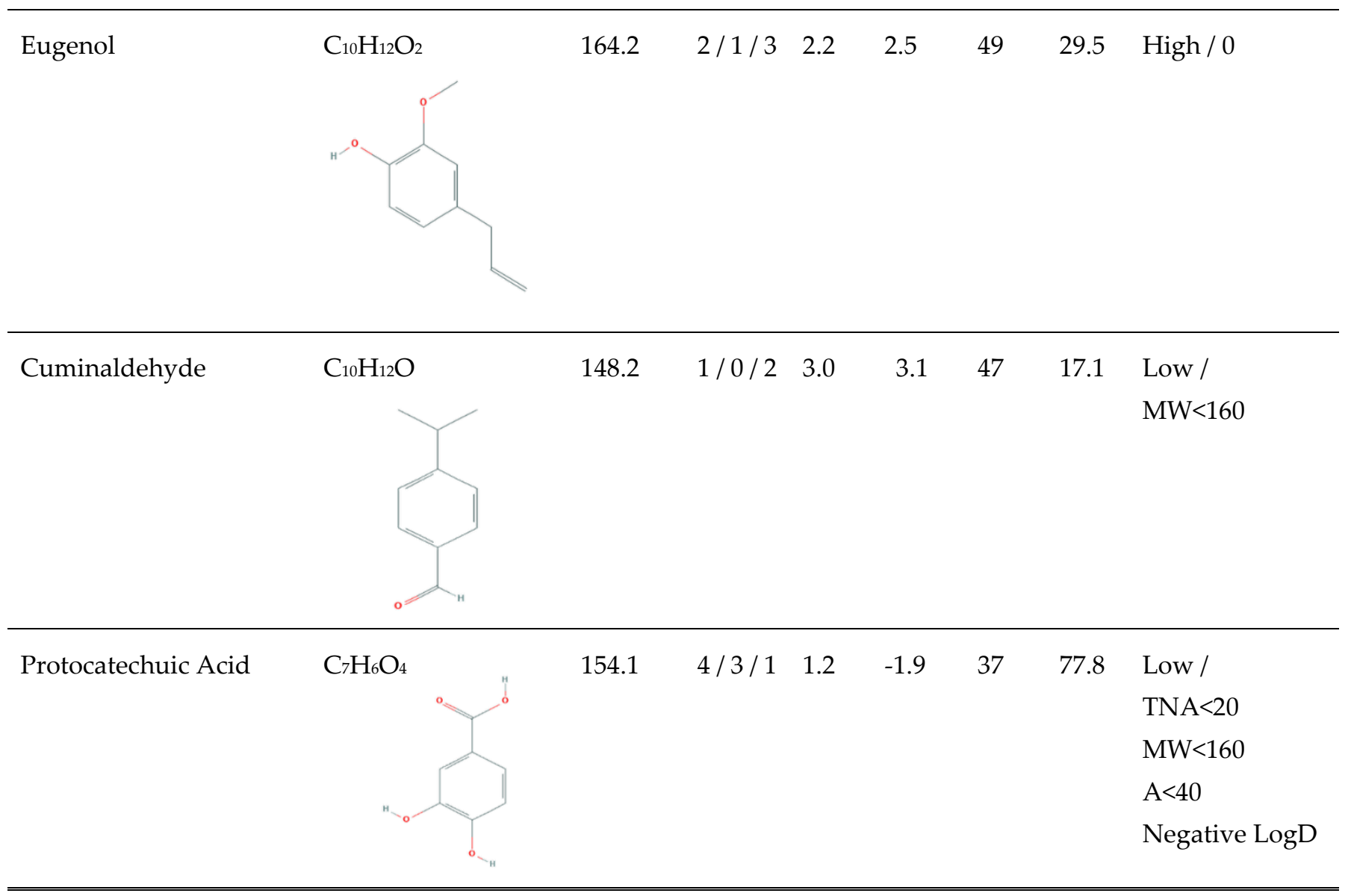

\section{Graviola}

\begin{tabular}{|c|c|c|c|c|c|c|c|c|}
\hline Benzylisoquinoline & $\mathrm{C}_{16} \mathrm{H}_{13} \mathrm{~N}$ & 219.3 & $1 / 0 / 2$ & 4.0 & 4.3 & 72 & 12.9 & High / 0 \\
\hline Annonacin /Acetogenin & $\mathrm{C}_{35} \mathrm{H}_{64} \mathrm{O}_{7}$ & 596.9 & $7 / 4 / 26$ & 6.4 & 7.3 & 169 & 116 & $\begin{array}{l}\text { Low / } \\
\text { TNA }>70 \\
M W>500 \\
\text { RB }>10 \\
\text { LogP }>5.6 \\
\text { A }>130 \\
\text { High LogD }\end{array}$ \\
\hline
\end{tabular}




\begin{tabular}{|c|c|c|c|c|c|c|c|c|}
\hline Cinnamic Acid & $\mathrm{C}_{9} \mathrm{H}_{8} \mathrm{O}_{2}$ & 148.2 & $2 / 1 / 2$ & 2.4 & -0.7 & 44 & 37.3 & $\begin{array}{l}\text { Low / } \\
\text { TNA }<20 \\
\text { MW }<160 \\
\text { Negative LogD }\end{array}$ \\
\hline Coumaric Acid & $\mathrm{C}_{9} \mathrm{H}_{8} \mathrm{O}_{3}$ & 164.2 & $3 / 2 / 2$ & 2.4 & -1.4 & 46 & 57.5 & $\begin{array}{l}\text { High / } 0 \\
\text { Negative LogD }\end{array}$ \\
\hline Caffeic Acid & $\mathrm{C}_{9} \mathrm{H}_{8} \mathrm{O}_{4}$ & 180.2 & $4 / 3 / 2$ & 1.4 & -1.7 & 48 & 77.8 & $\begin{array}{l}\text { High / } 0 \\
\text { Negative LogD }\end{array}$ \\
\hline Rutin & $\mathrm{C}_{27} \mathrm{H}_{30} \mathrm{O}_{16}$ & 610.5 & $\begin{array}{l}16 / 10 / \\
6\end{array}$ & 1.8 & -1.8 & 138 & 266 & $\begin{array}{l}\text { Low / } \\
\text { TNA }>70 \\
M W>500 \\
H B A>10 \\
H B D>5 \\
A>130 \\
\text { PSA }>140 \\
\text { Negative LogD }\end{array}$ \\
\hline \multicolumn{9}{|c|}{ Oregano } \\
\hline Carvacrol & $\mathrm{C}_{10} \mathrm{H}_{14} \mathrm{O}$ & 150.2 & $1 / 1 / 1$ & 3.3 & 3.1 & 47 & 20.2 & $\begin{array}{l}\text { Low / } \\
M W<160\end{array}$ \\
\hline Thymol & $\mathrm{C}_{10} \mathrm{H}_{14} \mathrm{O}$ & 150.2 & $1 / 1 / 1$ & 3.3 & 3.1 & 47 & 20.2 & $\begin{array}{l}\text { Low / } \\
\text { MW<160 }\end{array}$ \\
\hline
\end{tabular}




\begin{tabular}{|c|c|c|c|c|c|c|c|c|}
\hline O-Cymene & $\mathrm{C}_{10} \mathrm{H}_{14}$ & 134.2 & $0 / 0 / 1$ & 4.0 & 4.1 & 45 & 0 & $\begin{array}{l}\text { Low / } \\
M W<160\end{array}$ \\
\hline Apigenin & $\mathrm{C}_{15} \mathrm{H}_{10} \mathrm{O}_{5}$ & 270.2 & $5 / 3 / 1$ & 2.1 & 1.3 & 70 & 87 & High / 0 \\
\hline Luteolin & $\mathrm{C}_{15} \mathrm{H}_{10} \mathrm{O}_{6}$ & 286.2 & $6 / 4 / 1$ & 2.4 & 1.1 & 72 & 107 & High / 0 \\
\hline
\end{tabular}

MW: molecular weight; S: aqueous solubility; LogP: lipophilicity; LogD: lipophilicity considering ionizable groups at pH 7.4; A: molar refractivity; HBD: Hydrogen bond donors, HBA: Hydrogen bond acceptors; RB: rotatable bonds; PSA: polar surface area; TNA: total number of atoms; L-Ro5: Lipinski's Rule of 5; GF: Ghose Filter; VR: Veber's Rules

Predicted data of Empirical formula, Structure, MW (Da), H-bond Acceptor / Donor, Log P, Log D, and A were generated using PubChem [26], ChemSpider [28], ACD/Labs Percepta Platform - PhysChem Module [29] and US Environmental Protection Agency's EPISuite ${ }^{\mathrm{TM}}$ [30].

Favorable properties or "drug-likeness" for GI tract absorption are predicted by the combination of L-RO5, GF, and VR: MW (160-500 Da); HBD $\leq 5 ; \mathrm{HBA} \leq 10 ; \mathrm{A}(40-130) ; \operatorname{LogP}(-0.4-5.6) ; \mathrm{RB} \leq 10$ : PSA<140; TNA (20-70) [27].

\subsection{Turmeric}

\subsubsection{Botanical Description}

Turmeric, also known as Curcuma longa, is a rhizomatous herbaceous perennial plant that belongs to the Zingiberaceae family (ginger family). This plant is highly branched with aromatic long leaves arranged in two rows. Turmeric flowers have colors ranging from white, green, yellowish, and purple-red [31]. Curcuma plants are wildly cultivated in Southeast Asia and the Indian region where is used mainly for herbal medicinal applications, dietary supplement, and cuisine purposes [32,33]. The most essential part of turmeric used as a spice and herbal supplement is the rhizome in the roots of the plant. Turmeric powder has a pungent taste and distinctive yellow/orange color due to pigments and curcuminoids phytochemicals in the rhizome [34]. Furthermore, primary metabolites (e.g., proteins and fats) and phytochemicals concentration, which dictate other physical properties and the color intensity of the turmeric powder, depending on factors like the type of soil, crop fertilizers, and $\mathrm{pH}$ [35].

\subsubsection{Phytochemicals}

Turmeric's therapeutic properties may include a wide variety of conditions found in the literature, where most of them come from the bioactive compounds in its rhizome. For years different research groups have shown that turmeric is extraordinarily rich in valuables phytochemicals with pharmacological properties including polyphenols (e.g., curcuminoids), terpenes (e.g., ar-, $\alpha$ - and $\beta$-turmerone, $\alpha$-zingiber, and $\beta$-sesquiphellandrene), flavonoids, coumarins, saponins, tannins, and steroids [36-38]. The principal curcuminoids are curcumin and its derivatives demethoxycurcumin and bisdemethoxycurcumin $[32,39,40]$. Curcumin is considered the major bioactive phytochemicals from turmeric and is around 5\% of the rhizome. Some other bioactive compounds found in 
essential turmeric oils are aromatic-tumerones, $\alpha$-santalene, and aromatic curcumene $[41,42]$. The biomedical uses of curcumin are limited by its short half-life, low stability, and limited bioavailability are its short half-life, low stability, and poor bioavailability [43]. However, there are different strategies under investigation to overcome these limitations, as the use of natural enhancers and the development of delivery systems to encapsulate the curcumin $[44,45]$. Various studies have demonstrated that primary and secondary metabolites in turmeric extracts may enhance the bioavailability of curcumin in vivo $[43,46]$. Some other phytochemicals in combination with curcumin have shown synergistic effects increasing its bioavailability, e.g., quercetin, genistein, terpineol, epigallocatechin3-gallate, and resveratrol $[47,48]$.

\subsubsection{Biomedical effects}

\subsubsection{Anticancer}

Turmeric extracts and isolated curcumin have been extensively studied for cancer applications. Since 1985, turmeric extracts have demonstrated potent cytotoxic activity against cancer in vitro and in vivo [49]. Then, it also entered clinical studies for the treatment of cancer [50]. Curcumin has been shown to diminish tumor growth effectively, prevent tumor formation, angiogenesis, migration, and invasion by modulating several cell signaling pathways related to adhesion molecules, cell survival proteins, growth factors, transcription factors, cytokines, kinases, and receptors [51]. Different studies demonstrated that curcumin downregulates cyclin D1, cyclin E and MDM2, and upregulates p21, p27, and p53 [52]. Due to the low bioavailability of pure curcumin, some researchers prefer to continue studies using turmeric extracts, co-administration with other phytochemicals, or the development of drug delivery systems. For example, Li et. al., reported that turmeric extracts $(200 \mathrm{mg} / \mathrm{kg})$ induced in vivo tumor growth inhibition and anti-metastatic effects using colorectal CT26, HT29, and HCT116 cancer cells [53]. Also, in combination with the phytochemical quercetin, it reveals a synergistic effect against lung, skin, colorectal, and breast cancer cells [54]. In addition, Almutairi et. al., designed the encapsulation of curcumin in a chitosan polymer nanoparticle $(115 \mathrm{~nm})$ to determine its anticancer activity. This curcumin-chitosan nanoparticle showed a sensitive release in more acidic $\mathrm{pH}$ as in cancer environment [55] are much more anticancer studies using curcumin and explaining its mechanism of action in the literature: [56-60].

\subsubsection{Antioxidant}

Curcumin is an extremely potent antioxidant by inhibiting the formation of reactive oxygen species [61]. In an in vitro study, Ak and Gülçin demonstrated the potent radical scavenging activity of curcumin by inhibiting $>95 \%$ of lipid peroxidation [62]. Yuliani et. al., investigated the antioxidative and neuroprotective effects of curcuminoids on neurons from Sprague-Dawley rats as a potential treatment for dementia. Turmeric extract (200 $\mathrm{mg} / \mathrm{kg}$ ) prevents spatial memory deficits, and its effects were comparable to the standard dementia medicine, citicoline [63]. In addition, Hossen et. al., demonstrated the antioxidant properties and protective effects to hepatic organs in orally supplemented rats through a combination of curcumin $(62 \%)$, flavonoids (37\%), and ascorbic acid (10\%). The possible mechanism of action was through antioxidant enzyme upregulation and lipid peroxidation inhibition providing protecting effects [64].

\subsubsection{Antiviral}

Several studies have demonstrated that the turmeric plant and the isolated phytochemical curcumin have exhibited activity against a wide variety of viruses due to its potential to interfere with different cellular signaling pathways, inhibiting virus proliferation and viral expression [65]. The list of viruses that turmeric demonstrated activity are Influenza A, Dengue, Viral hemorrhagic septicemia, Human immunodeficiency, Herpes simplex, Enterovirus 71, Zika, Chikungunya, Vesicular stomatitis, Human respiratory syncytial, and others [66]. In general, curcumin strongly inhibits virus proliferation and expression before it was able to infect the cells. An in vitro study focused on the structureactivity relationship demonstrated that double bonds in the central carbon chain 
enhanced the curcumin activity against type A influenza virus by its interaction with the receptor-binding region [67]. On the other hand, in another study, researchers claimed that the hydroxyl groups and phenyl rings of curcumin are responsible for the antiviral effect against the herpes simplex virus [68]. Curcumin showed an excellent inhibitory effect in the micromolar rage against transmissible gastroenteritis virus in cells in a dose-, temperature- and time-dependent manner [69]. In a very recent systematic review, Kunnumakkara et. al., explained the potential of curcumin and other spices against SARS$C O V-2$ due to their anti-inflammatory properties to inhibit the cytokine storm [70]. These findings suggest that turmeric extracts not only could be a potential treatment but also a prevention alternative for viral infections.

\subsubsection{Anti-inflammatory}

Turmeric also exhibited potential to treat chronic pain and joint inflammation [71]. In a study using turmeric extracts in combination with Allium hookeri extracts, researchers determined that this co-treatment restored the altered skin membrane and inhibits white blood cells and monocyte proliferation in inflamed skin models [72]. Bethapudi et. al., demonstrated that oral administration of turmeric extract containing $57 \%$ of the bioactive turmerosaccharides significantly reduced pain and inflammation effects on an animal model (mimicking human osteoarthritis). This turmeric extract revealed a similar analgesic effect to tramadol on osteoarthritis pain [73]. In a recent study, Nicoliche et. al., summarized the following curcumin's mechanisms of action against the inflammatory process: inhibition of NF-KB (nuclear factor kappa B), MMP-1, 3, 8, 9, and 13 (matrix metalloproteinases), nitric oxide synthase, MAPK (mitogen-activated protein kinase), MCP (monocyte chemoattractant protein), STAT (signal transduction and activation transcription), PI3K (phosphoinositide 3-kinase), lipo-oxygenase, JAK (Janus kinase), and COX-2 (cyclo-oxygenase-2), MIP (migration inhibitory protein); also inhibition on the expression of interleukin-1, $-2,-6,-8,-12$ and $-1 \beta$, and TNF- $\alpha$ (tumor necrosis factor- $\alpha$ ); significantly improve collagen repair [74]. It is also postulated that curcumin upregulates the peroxisome proliferator-activated receptor- $\gamma($ PPAR- $\gamma)$ [75].

\subsubsection{Antibacterial}

There are also reports showing the antibacterial activity of turmeric [37]. Bangun et. al., developed an alginate-based drug delivery system of turmeric extract and tested its activity against Staphylococcus aureus (gram-positive) and Escherichia coli (gram-negative). The results showed that this turmeric drug delivery system affected both strains. However, there was more prominent growth inhibition on the gram-positive bacteria than on the gram-negative [76]. Another study performed by Czernicka, and colleagues elucidated the antimicrobial potential of turmeric extract against several Gram-positive strains (one strain of Staphylococcus epidermidis and two strains of Bacillus subtilis), revealing that the different fractions of this extract can inhibit bacterial growth [37]. In the same way, Shakeri et. al., confirmed that gram-positive bacteria are more sensitive to curcumin than gram-negative bacteria due to their abundant hydrophilic lipopolysaccharide's outer membrane [77].

\subsubsection{Antifungal}

Another significant effect of turmeric is its antifungal activity. Chen et. al., showed that turmeric extracts have potent antifungal activity against 20 pathogenic fungi (e.g. Fusarium verticillioides, Curvularia pallescens, Colletotrichum falcatum, Aspergillus niger, Aspergillus terreus, Fusarium oxysporum, Fusarium moniliforme, Fusarium graminearum, Phoma wasabiae, Alternaria alternate, Botrytis cinerea, Chaetomium olivaceum, Penicillium pallidum, Mycogone perniciosa, and Verticillium dahlia) by disrupting the synthesis of the main components of the fungal cell wall and interfering the protein synthesis. From this study, phytochemicals in turmeric have better antifungal activity working in combination than individual compounds [78]. Murugesh and colleagues elucidated that turmeric extracts exhibit a potent anticandidal effect against Candida albicans on in vitro studies [79]. In a randomized clinical trial, researchers demonstrated that the topical administration of 
curcumin 5\% ointment can significantly reduce knee pain in osteoarthritis patients [80]. This suggests the consideration of turmeric topical use as a low-cost alternative with lesser side effects considering its antifungal capacity.

\subsubsection{Immunological}

As previously described, curcumin has antioxidant and anti-inflammatory properties leading to improve immune response. In in vivo experiments to study Graft-versus-Host Disease (induced after bone marrow transplantation), mice were pretreated with curcumin $(100 \mu \mathrm{g} / \mathrm{mouse})$. These curcumin-pretreated mice showed an increase in CD4+ and CD8+ cells before the transplant preventing the disease [81] Jian et. al., studied the effects of curcumin as a dietary supplement in the male Hu sheep model, reporting changes in blood metabolites, antioxidant capacity, testicular development, and immune response. After four months of dietary supplementation, the sheep showed an improvement in the reproductive system performance [82]. In vivo and clinical studies indicate that curcumin can positively affect several immune cells (i.e., T lymphocyte subsets, macrophages, dendritic cells, B lymphocytes, and natural killer cells) which diminishes the severity of different autoimmune diseases [83]. Additional studies found promising results in patients with several pro-inflammatory illnesses (i.e., cardiovascular disease, renal diseases, arthritis, Crohn's disease, ulcerative colitis, irritable bowel disease, pancreatitis, peptic ulcer, gastric ulcer, oral lichen planus, vitiligo, psoriasis, acute coronary syndrome, atherosclerosis, diabetes, lupus, acquired immunodeficiency syndrome, $\beta$-thalassemia, biliary dyskinesia, and Dejerine-Sottas disease) [84].

\subsubsection{Contraindications}

Despite the extent of evidence that reveals the beneficial effect of Curcuma longa extract, there might be several side effects and contraindications associated with its use. Previous studies reported that turmeric extract could increase bile secretion, trigger biliary colic to predispose patients with gallstones [85]. Besides, taking turmeric in abundance for extended periods may cause gastrointestinal ulcers [86]. In addition, it was reported that a high dose of turmeric supplementation was related to inducing atrioventricular block in patients, which disappeared once the supplementation was discontinued [86]. Furthermore, turmeric supplementation may increase the risk of bleeding if it is taken in combination with anticoagulant drugs [87]. Moreover, turmeric extract is not recommended to certain diabetic patients due to anti-hyperglycemic and insulin sensitizer effects [88]. Due to curcumin's iron chelating property, it is not recommended to a patient with iron deficiency [89].

\subsection{Garlic}

\subsubsection{Botanical Description}

Central Asia is considered the home of garlic (Allium sativum), a member of the Amaryllidaceae family, even though it has been farmed for a long time worldwide. Garlic is a perennial plant that produces edible bulbs from a tall stem of $25-70 \mathrm{~cm}$ and can be grown in mild climates [90]. Garlic bulbs are composed of various cloves, and those who have flowers are hermaphrodites (some varieties do not produce flowers) [91]. Its leaves and cloves have been used as a spice and food additive and in traditional medicine for a long time [92]. Garlic has two major subspecies: hardneck (produce flower stalks and results in a bulb circle of 6-11 cloves) and softneck (produce no flowers and the bulb circle can result in 24 cloves [93-94]. Garlic's cultivars are divided into eight subtypes (rocambole, marble purple, purple stripes, porcelain, glazed purple stripe, Asiatic, Creole, and turban) for hardneck and into two subtypes (artichoke and silverskin) for softneck [94]. Alliums like garlic produce a pungent odor when crushed [94]. Interest in the potential benefits of this plant originates in antiquity (up to 5,000 years ago) and is one of the earliest documented examples of plants used for health maintenance and treatment of disease [95].

2.2.2. Phytochemicals 
Garlic is composed of various phytoconstituents, including alkaloids, saponins, flavonoids, tannins, phenolics, terpenoids, and organosulfides [96]. In addition, garlic is considered a good source of vitamins and minerals, including vitamin B1, B6, C, manganese, copper, phosphorus, selenium, and calcium. [97]. Garlic's main phytochemicals are organosulfides (sulfur-containing compounds) including allicin, alliin, ajoenes (E-ajoene and Z-ajoene), sulfides (diallyl sulfide, diallyl disulfide, diallyl trisulfide), 2-Vinyl-4H-1,3dithiin, and allyl methyl sulfide [98,99]. These organosulfides are produced in garlic cloves [96]. Allicin is the primary bioactive phytochemicals present in the aqueous extract of garlic and is also responsible for the characteristic odor of garlic [93]. Thus, enzyme alliinase converts allicin to alliin when the garlic cloves are sliced/crushed [100]. For this reason, several studies have shown that crushed fresh garlic can deliver most of its active phytochemical [98, 101,102]. As allicin is chemically unstable, it rearranges into the stable phytochemical ajoene (E- and Z-) [103]. Allyl sulfides are most often found in garlic oil, and vinyl-4H-1,3-dithiin is most often found in stir-fried garlic and garlic oil [104,105].

\subsubsection{Biomedical effects}

\subsubsection{Anticancer}

Interestingly, phytochemicals such as garlic-derived allicin have been combined with commonly used anticancer drugs to enhance the therapeutic effect of current treatments. For example, an experiment performed by Bogdan et. al., showed that a combination of the anticancer drug, 5-fluorouracil with allicin, hindered colorectal (DLD-1) and lung cancer (SK-MES-1) cell migration and proliferation in vitro [106]. Petrovic et. al., studied the effectiveness of intraperitoneal injections of ethanolic homemade garlic extract against an aggressive breast cancer tumor in BalB/c mice. The results showed that after 28 days of treatment, cancer growth was delayed by 30\% compared with untreated mice. [107]. In another study, Tanaka et. al, led a randomized double-blinded study on 51 patients with colorectal adenomas that utilized high-aged garlic extract $(2.4 \mathrm{ml} / \mathrm{day})$ and low-aged garlic extract $(0.16 \mathrm{ml} /$ day $)$ for 12 months. At least one adenoma decreased by $50 \%$ (> 6 months of uptake) in the high-aged garlic extract group, while there was no decrease in the low-aged garlic extract group [108]. Finally, a recent meta-analysis of epidemiological articles using a total of 11 clinical trials and 12,558 cases concluded that garlic intake could reduce the risk of colorectal cancer [109], coinciding with previous studies [110], while another previous meta-analysis limited to men, showed no correlation [111]. These studies show that broader investigations with increased sample size are necessary to clarify the result discrepancies from several epidemiological studies.

\subsubsection{Antioxidant}

Garlic's phytochemicals also promote an antioxidant effect. Bhatt and Patel et. al., prepared $900 \mathrm{mg}$ of cooked versus raw garlic and incubated these samples with gastric enzymes. These results showed that cooked garlic lost $90 \%$ of phenolic content, leading to less antioxidant activity due to heat (evaporation of active compound) than raw garlic [112]. Lei et. al., demonstrated that the scavenging activity of black fermented garlic ethanolic extract is concentration-dependent in incubation with 1,1-diphenyl-2-picrylhydrazyl (DPPH) radical. This study also showed that this garlic extract increased the mean longevity of flies (Drosophila melanogaster) compared to controls [113]. In a more translational scenario, a randomized, double-blind clinical trial on seventy women with rheumatoid arthritis was made to test the effects of garlic in pain mitigation. Patients received 1000 $\mathrm{mg}$ of garlic for a total of 8 weeks. Results showed that pain after activities decreased in the garlic group compared to the placebo. This effect from garlic was attributed to a decrease in oxidative stress, which is a common feature in this disease [114].

\subsubsection{Antiviral}

Several studies have shown the antiviral effect of garlic. Pre-clinical studies elucidated that garlic and its organosulfides phytochemicals have great activity against several human and animal viruses by inhibiting viral RNA polymerase, reverse transcriptase, and downregulation of the extracellular-signal-regulated kinase/mitogen-activated protein 
kinase signaling pathway [115]. The variety of viruses attacked by garlic are adenovirus [116], SARS-CoV-1 [117], dengue [118], herpes simplex [119], influenza A, B, and H1N1 [120,121], hepatitis [122], HIV [123] and rotavirus [124]. Furthermore, in a very recent study, garlic essential oil was found to be acting on the angiotensin-converting enzyme 2 (ACE2) and largely on the main protease of SARS-CoV-2 (PDB6LU7). This activity is crucial to diminish the impact of the host receptor of $S A R S-C o V-2$, and this study proposes that garlic oil active compounds can be used as a COVID-19 preventive treatment [125].

\subsubsection{Anti-inflammatory}

The anti-inflammatory effect of garlic was studied by several research groups. In an in vitro study, Lee and coworkers showed garlic's anti-inflammatory activity at $\mu \mathrm{M}$ concentrations. They demonstrated that garlic's organosulfides Z- and E- ajoene and analogs inhibited nitric oxide/ prostaglandins and nitric oxide synthase/ cyclooxygenase, the phosphorylation of p38 mitogen-activated protein kinases and, also the expression of the pro-inflammatory cytokines: tumor necrosis factor- $\alpha$, interleukin- $1 \beta$, and - 6 in a lipopolysaccharide-induced macrophage cell line [126]. In a different study, Metwally et. al., investigated the anti-inflammatory effects of garlic extract and allicin in vivo in 140 female $\mathrm{BALB} / \mathrm{c}$ mice with schistosomiasis. It was shown that garlic and allicin diminished the number of worms and the amount of proinflammatory cytokines [127]. In a double-blind clinical trial study, anti-inflammatory effects in 40 peritoneal dialysis patients were investigated by administering a garlic extract twice daily for 8 weeks. The results demonstrated that garlic diminished inflammatory markers in end-stage renal disease patients, specifically interleukin-6, C-reactive protein, and erythrocyte sedimentation rate in the treated group [128].

\subsubsection{Antibacterial}

The antibacterial effect of garlic was analyzed in vitro using fresh garlic juice in agar plates against E. coli, P.mirabilis, K.pneumoniae, S.aereus, and P.aeruginosa. The results showed a dose-dependent inhibition in all bacterial strains exposed to a garlic concentration higher than 10\% [129]. In another study, two different aqueous garlic extracts (from Allium sativum and Allium tuberosum) were tested in rats infected with one penicillin-sensitive (ATCC 25923) and one methicillin-resistant (ATCC 33592) S. aureus. The two species of garlic were administered orally at 100 and $400 \mathrm{mg} / \mathrm{kg}$ ) every $6 \mathrm{hrs}$ for $24 \mathrm{hrs}$. Results showed that both garlic extracts could reduce the infection of the sensitive strain, but not against the resistant strain [130]. Thus, several in vitro studies demonstrated the antibacterial effect of fresh garlic extract on E. coli, Klebsiella pneumoniae, Proteus mirabilis, P. aeruginosa, and S. aureus [129]; and also, against multidrug-resistant E. coli, P. aeruginosa, K. pneumoniae, Serratia marcescens, and methicillin-resistant S. aureus [131]. In a clinical trial that involved 15 patients with Helicobacter pylori, the results showed that Urease Breath Test was lower in patients who took $3 \mathrm{~g}$ of garlic cloves twice a day, demonstrating its antimicrobial effect [132].

\subsubsection{Antifungal}

Various studies have discussed the antifungal effect of garlic. Li et. al., showed that in vitro experiments, garlic oil had an inhibitory effect against Candida albicans at a higher concentration of $0.35 \mu \mathrm{g} / \mathrm{ml}$ [133]. Aala et. al., performed an experiment that evaluated the structural characteristic of Trichophyton rubrum in response to garlic and allicin aqueous extracts. The results showed that the allicin extract was more effective in impeding the growth of fungal cells by changing fungi morphology [134]. In another in vitro study, results indicated that 0.125 and $0.0313 \%$ of garlic oil had a strong antifungal activity by penetrating hyphae cells and destroy their organelles against Penicillium funiculosum [135].

\subsubsection{Immunological}

The immune response induced by the garlic phytochemical, allicin, was studied in female BALB/c mice. Results showed that allicin treatment reduced parasitaemias and enhanced pro-inflammatory mediators during malaria infection in a dose-dependent manner [136]. In addition, Bruck et. al., studied the immune response of allicin in induced liver 
damage BALB/c male mouse. Results showed that allicin-treated mice showed decreased levels of the pro-inflammatory tumor necrosis factor- $\alpha$, aminotransferases, and improved hepatic necroinflammation [137]. A randomized, double-blind, clinical trial studied the immune and inflammatory effects of $3.6 \mathrm{~g}$ aged garlic extract administered daily in 51 obese adults for 6 weeks. Results showed that patients who took the extract supplementation had less pro-inflammatory cytokines like interleukin- 6 and tumor necrosis factor- $\alpha$ [138]. In a separate study, the immune effect of aged garlic extract supplementation was analyzed in a randomized, double-blind trial with 120 healthy participant adults to examine the proliferation of immune cells and the severity of symptoms during cold and flu season. Results showed that the garlic extract induced increased levels of NK cells, $\gamma / \delta-T$ cells, and reduced severity of symptoms, days, and incidence [139].

\subsubsection{Contraindications}

There is limited data about the safety of garlic supplements [140]. Hoshino et. al., administered $40 \mathrm{mg}$ of different garlic preparations to adult dogs. Results showed significant damage caused to gastric mucosa by raw garlic powder, gastric redness caused by boiled garlic powder, and no effect by raw garlic extract [141]. In 2014, the first case of pneumonia caused by fermented black garlic was discovered in a 77-year-old female patient who came into the hospital with shortness of breath and cough after taking black garlic. Also, she tested positive via a drug-induced lymphocyte stimulation test. The patient showed health improvement when she stopped taking black garlic [142]. In addition, the first case of drug-induced liver injury by the mild periportal cholestatic reaction was reported in a 43-year-old patient who suffered from hepatopulmonary syndrome following a liver transplant by taking a high dose of Allium sativum as treatment. The patient's liver enzymes returned to normal after discontinuation of the treatment [140]. According to the National Institutes of Health, garlic supplements may increase the risk of bleeding. It is contraindicated to take garlic supplements if the patient takes blood anticoagulants such as warfarin or if you will undergo surgery. These supplements could interfere with the effectiveness of specific drugs used as HIV treatments. Other side effects, especially with raw garlic, could include heartburn, upset stomach, and allergic reactions [143].

\subsection{Cinnamon}

\subsubsection{Botanical Description}

Cinnamon, appreciated for centuries for its peculiar flavor and aroma, is the dried inner bark of Cinnamomum verum (syn. C. zeylanicum Blume), an evergreen tree native of Sri Lanka and India. This C. verum is also commonly called as "true" cinnamon or Ceylon cinnamon. The Cinnamomum genus, which the cinnamons are part of, belongs to the laurel family (Lauraceae), and it includes about 250 evergreen aromatic trees and shrubs [144]. Most of the spice sold as cinnamon in the United States, however, comes from another cinnamon species, Cinnamonum cassia, also called Chinese cinnamon, because of its geographical origin in the mountains of China [145]. The botanical features of C. verum are summarized as trees (up to $50 \mathrm{ft}$ ) with long lance-shaped leaves, small yellow flowers organized in a cluster, and ovoid-shaped fruits. The botanical features of C. cassia are summarized as trees (up to $65 \mathrm{ft}$ ) with thin lance-shaped leaves, white flowers axial inflorescences, and globose drupe fruits [146].

\subsubsection{Phytochemicals}

Qualitative phytochemical screening of a methanolic extract from the bark of C. verum showed the presence of all four categories of secondary metabolites. It has also been shown that the phytoprofiles of the cinnamon extracts depends on the botanical part of the tree used for extraction; while essential oils from the $C$. verum bark mainly contain cinnamaldehyde and linalool, the flower and fruit extracts are enriched in (E)-cinnamyl acetate, and eugenol is the main compound of leaf extracts $[147,148]$. The bark of the cinnamon tree has also been reported to contain coumarin, a benzenoid lactone. C. cassia is particularly rich in coumarin (3462.0 mg/kg in C. cassia vs 12.3 to $143.0 \mathrm{mg} / \mathrm{kg}$ for C. verum) 
[149]. The solvent and temperature should also be carefully selected according to the molecule one wishes to extract, for example, water is a better solvent for extracting the phenols from C. verum than polar organic solvents at $200^{\circ} \mathrm{C}$ [150]. For Klejdus et. al., however, the factor for efficiently extracting mainly depends on the state of the destruction of the cinnamon cell structures during the extraction protocol [151].

\subsubsection{Biomedical effects}

\subsubsection{Anticancer}

In vitro and in vivo studies by Yang et.al., show that the essential oil of cinnamon extracted from the bark of $C$. cassia significantly inhibits the growth of head \& neck cancer cells and tumors in mice. The antitumor activity was believed to be mediated by the transcinnamaldehyde acting as a competitive inhibitor of the epidermal growth factor receptor (EGFR). This kinase is often mutated and overexpressed in many tumors and regulates key cancer metabolic pathways such as proliferation, apoptosis, angiogenesis, and tumor invasiveness [152]. Similarly, Koppikara et. al., reported that aqueous bark extract from C. cassia inhibits the growth of cervical carcinoma cells in a dose-dependent manner (IC 50 $=80 \mu \mathrm{g} / \mathrm{mL}$ ) by apoptosis and loss of mitochondrial membrane potential. The treated cells exhibited reduced migration potential by the downregulation matrix metallopeptidase 2 (MMP-2) and the EGFR. [153]. Furthermore, Perng et. al, demonstrated that C. verum component 2-methoxy-cinnamaldehyde had an antiproliferative effect on human hepatic adenocarcinoma both in vitro ( $\mathrm{IC}_{50}=25.72 \mu \mathrm{M}$ for $\left.48 \mathrm{~h}\right)$ and in vivo $(10-20 \mathrm{mg} / \mathrm{kg} / \mathrm{d}$ administration of 2-methoxy-cinnamaldehyde). The targeted metabolisms determined by this group were like the previous studies (i.e., mitochondrial apoptotic pathway), and activation of caspase-3 and -9, a sub-G1 phase cell cycle arrest and downregulation of nuclear factor$\mathrm{K} \beta(\mathrm{NF}-\mathrm{K} \beta)$ [154].

\subsubsection{Antioxidant}

A study on the peripheral blood mononuclear cells of rheumatoid arthritis patients showed that cinnamaldehyde and eugenol significantly reduced the levels of pro-inflammatory cytokines tumor necrosis factor- $\alpha$ (TNF- $\alpha)$ and interleukin- 6 . Also, these patients showed enhanced activity of the enzymes: superoxide dismutase, glutathione peroxidase, and catalase, suggesting an antioxidant effect. [155]. In the same way, Davaatseren et. al., demonstrated that trans-cinnamaldehyde diminish the production of nitric oxide and reactive oxygen species in macrophages [156]. Furthermore, cinnamon capsules were orally administered for 12 weeks in a small controlled clinical trial to women with polycystic ovary syndrome. This study demonstrated that cinnamon improved the antioxidant status and lipid profile of these patients by decreasing serum levels of malondialdehyde (derived from lipid peroxidation), total cholesterol, triacylglycerol, and increasing high-density lipoproteins. [157].

\subsubsection{Antiviral}

In vitro studies concluded that essential oil extracts from the leaves of C. verum extract had an antiviral effect in cells infected with the Influenza type A (H1N1) [158]. Similarly, a study by Moshaverinia suggests that a hydroalcoholic extract of $C$. verum at $1 \mathrm{mg} / \mathrm{mL}$ significantly reduces the viral titer of the human herpes simplex virus type 1 -infected cells [159]. Furthermore, in silico studies by Kulkarni et. al., suggest that cinnamaldehyde possesses a strong affinity to the $\mathrm{S} 1$ receptor binding domain of the spike (S) glycoprotein of the severe acute respiratory syndrome coronavirus 2 (SARS-CoV-2). Cinnamaldehyde could therefore be an efficient pharmacological agent to inhibit the entry of the virus into the host cells [160].

\subsubsection{Anti-inflammatory}

A study conducted in an in vitro human skin model for chronic inflammation and fibrosis suggests that a concentration of $0.0012 \%(\mathrm{v}: \mathrm{v})$ significantly inhibits the expression of genes involved in the inflammation and immune DNA damage responses. The authors attributed the effect to the cinnamaldehyde, and cinnamyl acetate, the two main chemical 
compounds present in the extract [161]. Likewise, Gunawardena et. al., have demonstrated that $C$. verum and $C$. cassia extracts inhibited the release of pro-inflammatory nitric oxide molecule and tumor necrosis factor protein in activated macrophages. From these results, the ethanolic extract from $C$. verum showed more activity than the aqueous extract $\left(\mathrm{IC}_{50}=36.4\right.$ and $122 \mu \mathrm{g} / \mathrm{ml}$, respectively). The phytochemicals with more anti-inflammatory effects were E-cinnamaldehyde and o-methoxycinnamaldehyde [161]. Furthermore, in an in vivo study, $4.5 \mathrm{ml} / \mathrm{kg}$ of the ethanolic cinnamon extract was orally administered to a mouse model for colitis. The treated mice exhibited significantly enhanced resorption of their colon fibrotic tissues and reduction of the fibrotic score associated with a decrease in the expression of extracellular matrix proteinases [162].

\subsubsection{Antibacterial}

Ahmed et. al., showed that aqueous, methanolic, and acetone extracts from C. verum bark exerted significant antibacterial effects on $S$. aureus, P. aeruginosa, and E. coli. The inhibitory effect of the extracts was believed to be mediated by cinnamaldehyde [163]. Furthermore, an in vivo study conducted on aquatic pathogens in zebrafish, Faikoh et. al., concluded significant antimicrobial effects of liposome-encapsulated cinnamaldehyde in fish-infected by A. hydrophilia, V. vulnificus, S. agalactiae, V. parahaemolyticus, and V. alginolyticus. The antimicrobial activity of the drug was associated with a decrease in the expression of the pro-inflammatory interleukin $-1 \beta,-6,-15$ and with an increase of the interleukin-10 [164].

\subsubsection{Antifungal}

In a 2019 study, Kowalska et. al., demonstrated the antifungal properties of $1 \%(\mathrm{v} / \mathrm{w})$ aqueous C. verum bark after a 6-day treatment against Botrytis cinerea, the mycelium responsible for the grey mold disease in tomato plants [165]. Furthermore, cinnamon seems to inhibit the growth of the microorganisms of the Candida family, which are responsible for most of the fungal diseases in humans. In a clinical trial study, Wang et. al., showed that an oil extract from $C$. verum significantly inhibited the growth of three species of $C$. albicans $(\mathrm{IC}=0.064 \mathrm{mg} / \mathrm{mL})$, C. tropicalis $(\mathrm{IC}=0.129 \mathrm{mg} / \mathrm{mL})$, and C. $\mathrm{krusei}(\mathrm{IC}=0.129 \mathrm{mg} / \mathrm{mL})$ [166]. Additionally, a study conducted on guinea pigs suggests that topical treatments with methanolic extracts of $C$. verum inhibit the growth of $M$. canis and T. mentagrophytes, two fungi involved in skin infections in animals and humans [167].

\subsubsection{Immunological}

Several studies have concluded that the phytochemicals present in cinnamon extracts inhibit the immune response associated with allergies. Mast cells, key effectors in allergic diseases, are considered promising therapeutic targets. Hagenlocher et. al., have shown that cinnamon extracts decrease the release and expression of pro-inflammatory mast cell mediators such as $\beta$-hexosaminidase, cytokines CXCL8, and chemokine ligand 2, 3, and 4 . From this study, the anti-allergic properties are believed to be mediated by cinnamaldehyde [168]. Similar results have been found in human and murine models for allergic inflammation. Cinnamon extracts significantly inhibited the allergen-specific $\mathrm{T}$ cell proliferation as well as TH1 and TH2 cytokine production [169].

\subsubsection{Contraindications}

While cinnamon possesses a large specter of medicinal properties, its regular consumption can also lead to adverse health effects. Ingestion of a big spoon of dry cinnamon spice may lead to scarring to airways, or even pneumonia [170]. Due to its apoptotic effect of cinnamaldehyde on B and T-cells, the consumption of cinnamon is contraindicated in patients under an immunotherapy treatment [171]. The consumption of cinnamon should be avoided during pregnancy since cinnamon can induce contractions and may lead to premature labor [172]. Importantly, studies conducted both in vitro and in vivo suggest that coumarin, abundant in C. cassia, is a potential carcinogen to individuals with mutations of the Cytochrome P450 2A6 [173].

\subsection{Graviola}




\subsubsection{Botanical Description}

A member of the Annonaceae/ Custard-apple family, Annona muricata, commonly known as soursop, graviola, paw-paw, or "guanabana" is a tree native to Central America and West Indies that is abundant at altitudes lower than $900 \mathrm{~m}$ above sea level. It is nowadays cultivated in tropical and subtropical climates in countries such as Angola, Brazil, Colombia, Costa Rica, Puerto Rico, India, and Venezuela [174]. The graviola tree is mainly appreciated for its edible fruit. Still, its parts (leaves, fruit, bark, root, etc.) have been commonly used in traditional pharmacopeia in the form of macerations, decoction, or as a topical medication $[175,176]$. While the graviola tree can grow in a large variety of soils, it prefers deep soils with good oxygenation [174]. Botanically speaking, its leaves are large and obovate to elliptically shaped, are green on top, and paler on under top with short petioles and a pungent smell. The tree produces yellow-greenish flowers and lags about two years in producing heart-shaped fruits. It usually bears fruits yearly from that point on and can produce up to ten fruits from its fifth year [177].

\subsubsection{Phytochemicals}

More than two hundred ( $>200)$ bioactive compounds have been isolated from the leaves, seeds, root, bark, fruit, and fruit peel of the graviola tree [176]. Most frequently identified are alkaloids, phenolics, and terpenoids $[178,179]$. Acetogenins are considered the main bioactive compound in the Annonaceae family, with over 120 acetogenins identified from the root, leaves, stems, fruit pulp, and the seed of the family members [180,181]. Acetogenins are a special class of secondary metabolites that could be considered part of the phenolics integrating polyketides and polyethers found exclusively in the plants of the Annonaceae family [182]. The structure of acetogenins is composed of a long carbon chain (35-38 carbons) as a fatty acid derivative. graviola leaves contain key medically relevant polyphenolics compounds, including quercetin, rutin, and gallic acid [183-185]. The leaves of graviola also contain close to eighty (80) essential oils, among which are bioactive sesquiterpenes, and compounds such as potassium, calcium, zinc, phosphorus, magnesium, carbohydrates, vitamin A, B, and C, phytosterol, and calcium oxalate [186,187].

\subsubsection{Biomedical effects}

\subsubsection{Anticancer}

Graviola anticancer activity has been extensively studied, and the cytotoxicity of graviola has been reported for several cancer types e.g., breast, colorectal, skin, head and neck, lung, liver, pancreatic, prostate cancer, and leukemia [174, 188-190]. Most of the antiproliferative properties of the extracts are believed to be mediated by the graviola acetogenins. The acetogenins exert an inhibitory activity on the NADPH mitochondrial complex 1 , a component of the energy transport chain, which is crucial to the synthesis of high quantities of ATP in cancer cells. [189,191,192]. Acetogenins have also been shown to target several critical cancer metabolic pathways by inhibiting the $\mathrm{Na}^{+} / \mathrm{K}^{+}$ATPase pump and the hypoxic and glycolytic pathways, inducing apoptosis and cell cycle arrest [192-194].

\subsubsection{Antioxidant}

Studies conducted in vitro and in vivo suggest that graviola contains antioxidant compounds that act as free-radical scavengers and increase the activity of the antioxidant enzymes superoxide dismutase and catalase and downregulate the function of mitochondrial NADPH oxidase complex I, [195-197]. The leaf and the fruit pulp of graviola are the parts of the tree with the highest antioxidant properties [178]. The antioxidant activity of graviola is believed to be mediated by the phenolic phytochemicals: quercetin, gallic acid, and graviola leaf polysaccharides [198,199].

\subsubsection{Antiviral}

It has been suggested that the phytochemicals polyphenolics in graviola exert some antiviral activity against RNA and DNA viruses $[185,200]$. A study by Wahab et. al., showed that pretreating monkey kidney epithelial cells with a graviola leaf extract $24 \mathrm{~h}$ prior to infecting them with the dengue virus serotype 2 , inhibited the virus replication. 
The treatment also increased the survival of the dengue-infected cells [201]. A recent clinical study conducted by Le Donne et. al., investigated the antiviral properties of graviola on human papillomavirus (HPV)-infected patients who were supplemented with ellagic acid and graviola extract twice a day for six months. Results showed a 74\% HPV clearance in treated patients compared to the $25 \%$ clearance for the placebo group [202]. Furthermore, recent in silico studies suggest that rutin, a phytonutrient abundant in graviola, could act as strong ligands and inhibit the function of proteins of the SARS-CoV and SARS$\mathrm{CoV}-2$ virus, thus suggesting potential therapeutic benefits against the COVID-19 infection $[203,204]$.

\subsubsection{Anti-inflammatory}

The anti-inflammatory properties of graviola have been extensively studied in vitro and in vivo [205]. Cercato et. al., reported that a topical application of a graviola leaf extract $(0.3,1$, or $3 \mathrm{mg} / \mathrm{ear})$ significantly reduced ear edema and myeloperoxidase activity in Swiss mice with 12-O-tetradecanoylphorbol-13-acetate (TPA)-induced ear inflammation. The authors were also able to show that the anti-inflammatory effect of the extract was associated with a reduction of the total amount of hydroperoxides, and with modulation of catalase antioxidant activity [206]. While studying the anti-inflammatory response in Lipopolysaccharide (LPS)-stimulated murine macrophage cell line RAW264.7 treated with graviola ethanolic leaf extracts, Laksmitawati et. al., reported a downregulation in the pro-inflammatory protein markers tumor necrosis factor-alpha (TNF- $\alpha$ ), interleukin$1 \beta$, interleukin-6 in the treated macrophages cells compared to untreated controls [207]. Furthermore, graviola aqueous extract suppresses nitric oxide production [208]. Similarly, an in vivo study conducted in rodents by Ishola et. al., showed that the administration of a lyophilized graviola fruit extract inhibits the activity of the pro-inflammatory biomarkers cyclooxygenase (COX)-1 and COX-2 in a dose-dependent manner [209].

\subsubsection{Antibacterial}

Graviola leaf extracts have been shown to exert an in vitro antibacterial activity against oral pathogenic strains such as S. mutants, S. mitis, P. gingivalis, P. intermedia, $P$. intermedia, and C. albicans [210,211]. An in vivo study conducted in albino rats demonstrated the efficiency of graviola unripe fruit extracts to inhibit the growth of S. typhi [212]. Furthermore, aqueous leaf extract and fruit-skin ethanolic graviola extracts showed a strong antibacterial effect against K. pneumoniae, S. aureus, and P. aeruginosa, bacteria, the pathogens responsible for respiratory infections in the Human Immunodeficiency Virus (HIV/AIDS) patients [213].

\subsubsection{Antifungal}

We did not find studies testing the antifungal activity of any graviola extract. However, we found studies evaluating this property in some of graviola's phytochemicals. In 2017 a research group found that gallic acid has in vitro antifungal activity against dermatophyte strains (between 43.75 and $83.33 \mu \mathrm{g} / \mathrm{mL}$ ), and Candida strains (C. albicans IC $=12.5$ $\mu \mathrm{g} / \mathrm{mL}$, and Trichophyton rubrum $\mathrm{IC}=43.75 \mu \mathrm{g} / \mathrm{mL}$ ) by inhibiting the ergosterol synthesis. They also confirmed this activity in vivo studies administrating $80 \mathrm{mg} / \mathrm{kg} \mathrm{d}$ of gallic acid [214]. In another study, researchers found that quercetin induces apoptosis in Candida albicans through mitochondrial dysfunction by increasing intracellular magnesium [215].

\subsubsection{Immunological}

Several studies have reported that graviola possesses immunomodulatory properties. For example, a study conducted in rodents by Umayra et. al., shows that administration of an ethanolic graviola leaf extract triggers a boost in the immunological response through the activation of phagocytic cells [216]. Furthermore, an immune-enhancing activity of graviola leaf extracts has been observed in RAW 264.7 macrophage cells in vitro, a phenomenon which is believed to be mediated by the activation of the mitogen-activated protein kinase (MAPK) pathways [217].

\subsubsection{Contraindications}


In vitro and in vivo studies suggest that the acetogenins and alkaloids present in the graviola fruit could be toxic to neurons [188]. While patients with neurological ailments should avoid consuming graviola altogether, the benefits/contraindication of graviola should be carefully evaluated on a case-by-case basis.

\subsection{Oregano}

\subsubsection{Botanical Description}

The term oregano refers to a group of several plant genera, including Thymbra, Thymus, Coridothymus, Satureja, and Origanum, containing a high amount of the phytochemical carvacrol in their essential oils. The genus Origanum consists of 43 species. Origanum vulgare (O. vulgare), commonly named "oregano", is the name of the aromatic plant used as a condiment herb in Mediterranean cuisine [218-220]. O. vulgare size is usually 20-80 $\mathrm{cm}$, its 1-4 cm leaves are dark green, with $2 \mathrm{~mm}$ bell-shaped calyx purple flowers arranged in erect spikes [221-223]. Like other aromatic plants, the oregano plant produces essential oils as secondary metabolites in response to various infectious agents, UV light, and even oxidative stress. Oregano essential oils (OEOs) are usually extracted from the plant leaves and flowering tops. OEOs are famous for their medicinal value and are traditionally used in Turkey to cure diseases like cough, chronic cold, wounds, gastrointestinal disorders, and skin problems in humans and domestic animals [224].

\subsubsection{Phytochemicals}

The main bioactive compounds present in the OEOs are the aromatic oxygenated monoterpene thymol (5-methyl-2-(1-methylethyl) phenol) and its constitutive isomer carvacrol (5-isopropyl-2-methylphenol, 2-p-cymenol). The ratio of thymol/carvacrol varies according to the oregano plant's geographical location [225]. Both compounds are lipophilic, volatile, highly soluble in ethanol, and possess low densities [224, 226-228]. Other bioactive oregano phytochemicals include o-cymene (2-Isopropyltoluene), apigenin (4',5,7-trihydroxyflavone), and luteolin (7,3',4',5-tetrahydroxyflavone) [229,230]. Due to their general low toxicities, the two main chemicals of O. vulgare, thymol and carvacrol have been approved as food additives by the Food and Drug Administration (FDA) [231].

\subsubsection{Biomedical effects}

\subsubsection{Anticancer}

The antiproliferative/anticancer properties of oregano have been documented in vitro and animal models for cancers. A recent study by Spyridopoulou et. al., showed that OEO exerts dose-dependent cytotoxicity against breast cancer (MCF-7), colon cancer cells (HT29), melanoma (A375), and hepatocellular carcinoma (HepG2) cells, with respective $\mathrm{IC}_{50}$ values of $0.35,0.35,8.90$, and $10.0 \mathrm{mg} / \mathrm{mL}$. The authors also showed that the treatment of HT-29 cells with $50 \mathrm{mg} / \mathrm{mL}$ of OEO correlated with an attenuated migration and an induced apoptosis-related morphological change in HT-29 cells. Furthermore, the oral administration of OEO for 13 days $(0.370 \mathrm{~g} / \mathrm{kg}$ b.w/day) proved to inhibit the growth of CT26 colon tumors in vivo in BALB/c mice [232]. Another study by Coccimiglio reports that an ethanolic leaf extract of $O$. vulgare promotes the death of A549 human lung carcinoma in a dose-dependent manner $\left(\mathrm{IC}_{50}=14.0 \mu \mathrm{g} / \mathrm{mL}\right)$ [233]. The antiproliferative properties of oregano are believed to be mediated by thymol and carvacrol, which possess antioxidant characteristics while being non-mutagenic to cells [233-235]. The anticancer properties of thymol were evidenced in in-vitro and in vivo models for colorectal cancers [236,237]. One astonishing property of carvacrol is its potential to specifically target cancer cells while being less toxic to normal cells [238]. Furthermore, carvacrol seems to exert a modulatory effect on the toxicity of cisplatin in vitro, a property that could be exploited for reducing the side-effects associated with classical cisplatin-based antitumor treatments [235].

\subsubsection{Antioxidant}

An in vitro study by Gavaric et. al., showed that OEO possessed a strong antioxidant activity $\left(\mathrm{IC}_{50}=0.2 \mu \mathrm{g} / \mathrm{mL}\right)$. While thymol and carvacrol were the components accounting 
for the antioxidant properties of oregano, the antioxidant activities of the two compounds were much inferior to the one observed for the whole extract with ( $\mathrm{IC}_{50}=70-80 \mathrm{mg} / \mathrm{mL}$ for thymol and carvacrol). The authors concluded that thymol and carvacrol, and other extract phytocompounds acted in synergy to promote the scavenging of free radicals [239]. According to a study conducted on the human colon carcinoma intestinal Caco-2 cell line, thymol, carvacrol, and their mixture seem to exhibit double-edged anti or prooxidant effects, depending on the concentration at which they are administered (pro-oxidants at sub-cytotoxic concentrations vs. antioxidants at higher concentrations) [240].

\subsubsection{Antiviral}

An in vitro study conducted on simian Vero cell line CCL-81 showed that thymol, carvacrol, and p-cymene (all major components of oregano oils) possess antiviral properties against the human herpes simplex virus type 1 with respective $\mathrm{IC}_{50}$ values of $0.002 \%$, $0.037 \%$, and $>0.1 \%$. The antiviral properties of the three compounds are believed to be correlated to their ability to interfere with the viral membrane fusion mechanism during the adsorption phase of the virus [241]. Furthermore, an in vitro study by Sánchez \& Aznar have reported a dose-dependent titer inhibition of the feline calicivirus and the murine norovirus by thymol, in the 1-2\% (v:v) range concentrations [242].

\subsubsection{Anti-inflammatory}

OEOs possess a strong anti-inflammatory activity, a property that is believed to be mediated by its main active compounds: thymol and carvacrol. The impact of the OEOs on 17 protein biomarkers closely related to the inflammatory response. The results show dose-dependent inhibition of the expression of all the proinflammatory biomarkers. Carvacrol was reported to be the main constituent of the essential oil, making up $78 \%$ of the total composition of its weight [243]. The anti-inflammatory activity of thymol was also reported in vivo in BALB/c mice affected by LPS-induced endometritis [244].

\subsubsection{Antibacterial}

Thymol and carvacrol have been shown to exert antibacterial activities against grampositive and gram-negative bacteria [245]. In studies using thymol concentrations ranging from $26.5-52.9 \mathrm{mg} / \mathrm{cm}^{2}$ showed strong inhibitory activity against the S. aureus, B. subtilis, E. coli, and Salmonella enteritidis [246]. Studies performed by Du et. al., showed the following results: strong antibacterial activity of the OEOs, thymol, and carvacrol against E. coli, C. perfringens, and Salmonella strains. They also performed in vivo studies in 448 male broiler chicks by oral gavage using OEO. They found that OEO alleviated intestinal lesions and decreased E. coli populations [247]. In another study, oregano oil showed great antibacterial activity against the following multidrug-resistant bacteria: three Acinetobacter baumannii, three Pseudomonas aeruginosa, and four methicillin-resistant Staphylococcus aureus with inhibitory concentrations ranging from $0.08-0.64 \mathrm{mg} / \mathrm{ml}$ [248]. Another in vitro study shows that the use of OEO and carvacrol could curve Group A streptococci erythromycin-resistant bacterial infections [249].

\subsubsection{Antifungal}

The in vitro antifungal properties of OEO, thymol, and carvacrol in the $40-350 \mathrm{mg} / \mathrm{mL}$ ranges, have been reported in several studies against plant pathogenic fungi Colletotrichum acutatum and Botryodiplodia theobromae [250], against Penicillium digitatum and Penicillium italicum [251], against food-relevant fungi Cladosporium spp. and Aspergillus spp. [252], against longan pathogens, Lasiodiplodia spp., Phomopsis spp., Pestalotiopsis spp. and Geotrichum candidum [253], and against Fusarium verticillioides and Rhizopus stolonifera [254]. In a very recent study, Serna-Escolano et. al., determined that thymol and carvacrol encapsulated in the polymer 2-hydroxypropyl-beta-cyclodextrin were highly effective in reducing the growth rate of Geotrichum citri-aurantii (which causes sour rot in citrus fruits). Furthermore, an in vivo study conducted in Caenorhabditis elegans suggests that thymol possesses antifungal activity against Candida albicans, the most prevalent cause of fungal infections in humans [255].

2.5.3.7. Immunological 
De Santis et. al., have studied the immunomodulatory effects of several $50 \%(\mathrm{v} / \mathrm{v})$ hydroalcoholic $O$. vulgare extracts on human-derived dendritic cells type-1 and type-2 macrophages infected with $M$. bovis Bacille Calmette-Guérin. The authors showed that the hydroalcoholic extract stimulated the anti-mycobacterial innate immunity and limited the inflammatory response in all the tested cell types [256]. On the contrary, Gholijani et. al., showed that intraperitoneal injections of $80 \mathrm{mg} / \mathrm{kg}$ of thymol or carvacrol in BALB/c mice trigger an immunosuppressive response, a property that could be exploited for treating autoimmune diseases [257].

\subsubsection{Contraindications}

As detailed in this review, O. vulgare offers a large spectrum of health benefits. Caution should be taken, however, with its medical use due to some negative health effects of its most abundant chemical constituents: thymol and carvacrol. Tisserand et. al., have shown that thymol is an irritant to the mucosal membrane [258]. Furthermore, despite being non-toxic at low to moderate doses, thymol and carvacrol have shown to induce dose-dependent structural chromosomal aberrations in Rattus norvegicus, when administered at doses of $40 \mathrm{mg} / \mathrm{kg}$ and up [259].

\section{Discussion}

Phytochemicals are vital cofactors with powerful effects on the body, helping it regain functionality. As shown in this review, even though phytochemicals may have different mechanisms of action and different levels of effectiveness in the body, there are overlapping aspects such as antioxidant, anti-inflammatory, and metabolic corrective effects that produce a variety of positive physiological repercussions that favor the healthy state. The physiologic modulation induced by these phytonutrients and their phytochemicals produces functional changes that support repair mechanisms necessary to achieve the homeostasis or balance known as health.

The physicochemical properties calculated for the main phytochemicals in the phytonutrients studied in this review are based on the combination of Lipinski's, Ghose's, and Veber's rules (L-Ro5, GF, VR), described as an approximation for the pharmacokinetics of a molecule in the body [27]. Thus, a molecule whose structure falls out of the range of these rules is predicted to have poor absorption or permeation through the gastrointestinal system and low systemic bioavailability.

From the evaluation of 25 phytochemicals through the mentioned parameters (Table 1), 23 of them fulfill the requirements of L-Ro5 (HBD $\leq 5, \mathrm{HBA} \leq 10, \mathrm{MW} \leq 500, \operatorname{logP} \leq 5$ ) and VR (RB $\leq 10, P S A \leq 140)$, while 2 (annonacin /acetogenin and rutin from graviola) violated more than one parameter. Per GF, the compounds should meet the following: MW (160 - 480), $\log P(-0.4-5.6)$, A (40-130), TNA (20-70). Accordingly, 13 phytochemicals (curcumin, demethoxycurcumin, bisdemethoxycurcumin, and $\alpha$-turmerone from turmeric; alliin, allicin, and z-ajoene from garlic; (E)-cinnamyl acetate and eugenol from cinnamon; benzylisoquinoline, coumaric acid and caffeic acid from graviola; apigenin and luteolin from oregano) comply with Ghose's rules.

Considering GI tract absorption (Figure 2a) 54\% of all phytochemicals studied in this review (curcumin, demethoxycurcumin, bisdemethoxycurcumin, $\alpha$-turmerone, alliin, zajoene, (E)-cinnamyl acetate, eugenol, coumaric acid, caffeic acid, apigenin, and luteolin) met all rules and thus, have a higher probability of being highly absorbed. Based on L- 
(a)

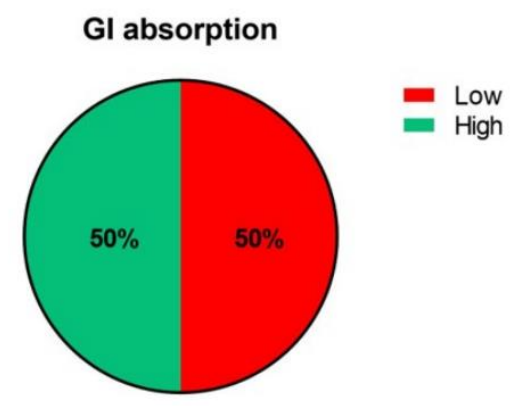

(c)

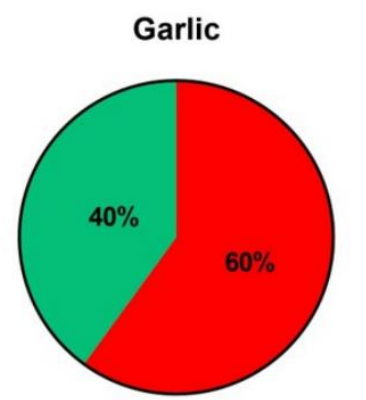

(e)
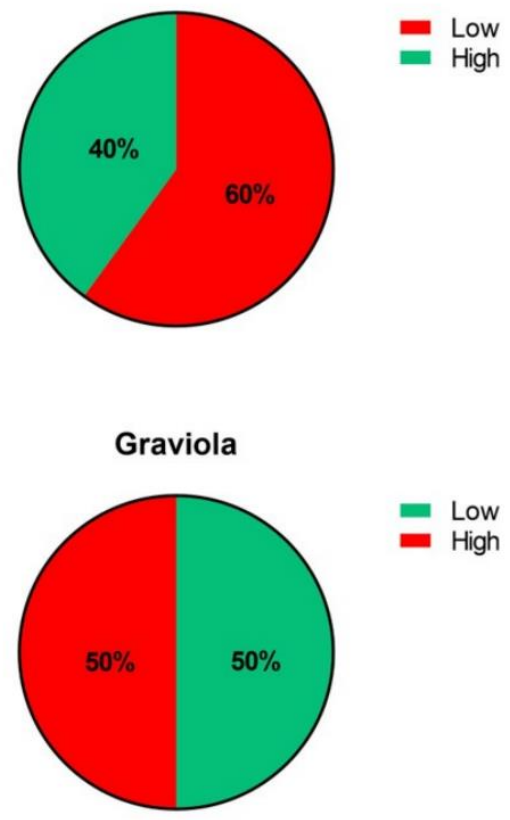

(b) Turmeric

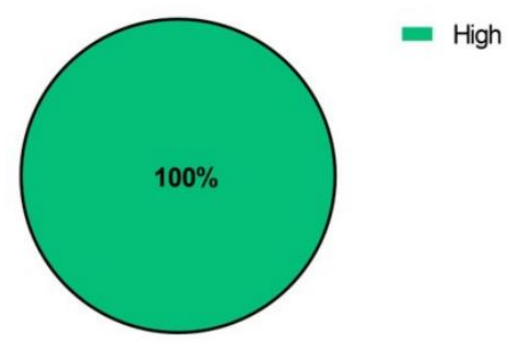

(d) Cinnamon

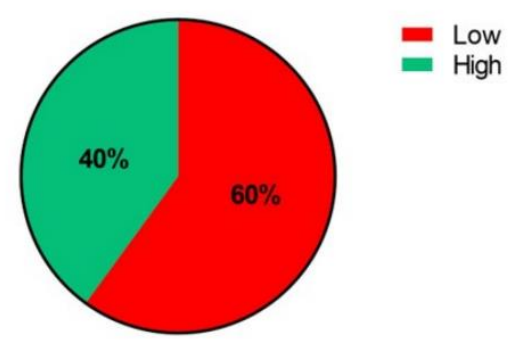

(f) Oregano

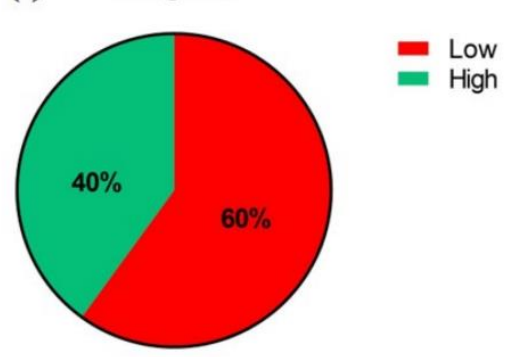

Figure 2. GI absorption for described phytochemical compounds. (a) Percent (\%) of phytochemicals of all selected phytonutrients with high or low probability for GI absorption. Percent (\%) of (b) Turmeric, (c) Garlic, (d) Cinnamon, (e) Graviola, and (f) Oregano phytochemicals with high or low probability for GI absorption.

Ro5, GF, and VR, all described turmeric's phytochemicals belong to highly absorbed compounds (100\%) compared to garlic, cinnamon, and oregano (40\%) (Figures $\mathbf{2 b}, \mathbf{2 c}, \mathbf{2 d}, \mathbf{2 f}$ ) and graviola (50\%) (Figure 2e).

Graviola's phytochemicals, annonacin /acetogenin, and rutin violate the majority of the "drug-likeness" rules. For example, annonacin /acetogenin complies with only 50\% LRo5 and VR and violates $100 \%$ of GF. For rutin, the compliance for L-Ro5 was $25 \%$, for GF was $25 \%$ and for VR was $50 \%$. Thus, it is predicted that annonacin /acetogenin and rutin have the lowest probability of being absorbed in the GI.

Other researchers have proposed that the lipophilicity considering the ionizable groups at $\mathrm{pH} 7.4(\log \mathrm{D})$ is much more important for physiological absorption or permeation [260]. Thus, compounds that fall below 1 and above 5 for $\log D$ are less likely to be absorbed. Based on this, alliin from garlic; protocatechuic acid from cinnamon; annonacin /acetogenin, cinnamic acid, coumaric acid, caffeic acid, and rutin from graviola fall out this LogD range.

However, the predictions of these rules are also based on molecules passively transported into the cells. This means that L-Ro5, GF, and VR do not take into consideration actively transported substrates by biological transporters (e.g., cellular receptors or channels) [261]. On the contrary, we understand that a large group of therapeutic compounds is actively transported in the organism, especially plant-based compounds. Due to this, 
other studies have shown that most of the violators of these rules are natural products [262]

\section{Conclusions}

All the phytonutrients mentioned in this review article, when used properly, have demonstrated a large variety of health benefits. Yet, a medical evaluation is needed before any decision is made on utilizing phytonutrients and phytochemicals regularly or in combination with another medical pharmacological treatment.

\section{Patents}

$\mathrm{N} / \mathrm{A}$

\section{Supplementary Materials: N/A}

Author Contributions: Coordination, Y.D.; conceptualization, Y.D.; formal analysis, Y.D., I.J.S.A.; theoretical calculations, Y.D., A.T., D.P., E.V., J.V.; writing-original draft preparation, Y.D., J.A., C.C.R., J.C.F., W.M., G.R., J.C.; A.T., C.B.; writing-review and editing, Y.D., C.C., Y.F.A., Z.T.M., R.A.V.A., J.R.Z., M.G.; supervision, Y.D. All authors have read and agreed to the published version of the manuscript.

Funding: This study was funded by the Career Development Grant (Y.D., Y.F.A.) from Sloan Scholars Mentoring Network, Biomedical Fellowships from Fundación Intellectus (Z.T.M., J.V. and Y.D.), and PR INBRE P20 GM103475-17 (I.J.S.A.).

\section{Institutional Review Board Statement: N/A}

Informed Consent Statement: N/A. Data Availability Statement: N/A

Acknowledgments: This publication was made possible by the support of the San Juan Bautista School of Medicine (SJBSM), Universidad Ana G. Méndez-Gurabo Campus, Universidad Central del Caribe (UCC), Fundación Intellectus, and University of Puerto Rico (UPR) System: Medical Sciences Campus, Mayaguez Campus, Bayamón Campus, and Rio Piedras Campus. The authors thank Dr. Estela Estapé (Director of the SJBSM Research Center) for her outstanding dedication and support in the writing process of this review.

Conflicts of Interest: The authors declare no conflict of interest. The funders had no role in the design of the study; in the collection, analyses, or interpretation of data; in the writing of the manuscript, or in the decision to publish the results.

\section{Appendix A}

$\mathrm{N} / \mathrm{A}$

\section{Appendix B}

N/A

\section{References}

1. Doosti, F.; Dashti, S.; Tabatabai, S. M.; Hosseinzadeh, H. Traditional chinese and indian medicine in the treatment of opioiddependence: A review. Avicenna J Phytomed 2013, 3 (3), 205-215.

2. Pan, S. Y.; Litscher, G.; Gao, S. H.; Zhou, S. F.; Yu, Z. L.; Chen, H. Q.; Zhang, S. F.; Tang, M. K.; Sun, J. N.;Ko, K. M. Historical perspective of traditional indigenous medical practices: The current renaissance and conservation of herbal resources. Evid Based Complement Alternat Med 2014, 2014, 525340.

3. Senti, S.; Habicht, M.E.; Rayo, E.; Eppenberger, P.E.; Rühli, F.J.; Galassi, F.M. Egyptian canopic jars at the crossroad of medicine and archaeology: Overview of 100 years of research and future scientific expectations. Pathobiology 2018, 85 (5-6), $267-275$.

4. Molyneux, R. J.; Lee, S. T.; Gardner, D. R.; Panter, K. E.jJames, L. F. Phytochemicals: The good, the bad and the ugly? Phytochemistry 2007, 68 (22-24), 2973-2985.

5. Koche, D.; Shirsat, R.; Kawale, M. An overerview of major classes of phytochemicals: Their types and role in disease prevention. Hislopia J 2016, 9, 1-11.

6. Reis Giada, M. D. L., Food phenolic compounds: Main classes, sources and their antioxidant power. InTech: 2013. 
7. Boeing, H.; Bechthold, A.; Bub, A.; Ellinger, S.; Haller, D.; Kroke, A.; Leschik-Bonnet, E.; Müller, M. J.; Oberritter, H.; Schulze, M.; Stehle, P.; Watzl, B. Critical review: Vegetables and fruit in the prevention of chronic diseases. Eur J Nutr 2012, 51 (6), 637663.

8. De Lima, R. M. T.; Dos Reis, A. C.; de Menezes, A. P. M.; Santos, J. V. O.; Filho, J.; Ferreira, J. R. O.; de Alencar, M.; da Mata, A.; Khan, I. N.; Islam, A.; Uddin, S. J.; Ali, E. S.; Islam, M. T.; Tripathi, S.; Mishra, S. K.; Mubarak, M. S.; Melo-Cavalcante, A. A. C. Protective and therapeutic potential of ginger (zingiber officinale) extract and [6]-gingerol in cancer: A comprehensive review. Phytother Res 2018, 32 (10), 1885-1907.

9. Njambi M., K. S., Nguka G, Olutende Oloo M, Kathure D, Wangari P. The role of phytochemicals in prevention and control of chronic diseases. Int J Curr Res 2017, 9 (12), 62540-62543.

10. Napolitano, G.; Fasciolo, G.; Di Meo, S.; Venditti, P. Vitamin e supplementation and mitochondria in experimental and functional hyperthyroidism: A mini-review. Nutrients 2019, 11 (12), 2900.

11. Reddavide, R.; Rotolo, O.; Caruso, M. G.; Stasi, E.; Notarnicola, M.; Miraglia, C.; Nouvenne, A.; Meschi, T.; De' Angelis, G. L.; Di Mario, F.; Leandro, G. The role of diet in the prevention and treatment of inflammatory bowel diseases. Acta Biomed 2018, 89 (9-s), 60-75.

12. Salas-Salvadó, J.; Becerra-Tomás, N.; Papandreou, C.; Bulló, M. Dietary patterns emphasizing the consumption of plant foods in the management of type 2 diabetes: A narrative review. Adv Nutr 2019, 10, S320-s331.

13. Kourouma, V.; Mu, T.-H.; Zhang, M.; Sun, H.-N. Effects of cooking process on carotenoids and antioxidant activity of orangefleshed sweet potato. LWT 2019, 104, 134-141.

14. Palermo, M.; Pellegrini, N.; Fogliano, V. The effect of cooking on the phytochemical content of vegetables. J Sci Food Agric 2014, 94 (6), 1057-1070.

15. Chen, F.; Wen, Q.; Jiang, J.; Li, H. L.; Tan, Y. F.; Li, Y. H.; Zeng, N. K. Could the gut microbiota reconcile the oral bioavailability conundrum of traditional herbs? J Ethnopharmacol 2016, 179, 253-264.

16. Zimmermann, G. R.; Lehár, J.; Keith, C. T. Multi-target therapeutics: When the whole is greater than the sum of the parts. Drug Discov Today 2007, 12 (1-2), 34-42.

17. Xu, W.; Wen, M.; Yu, J.; Zhang, Q.; Polyakov, N. E.; Dushkin, A. V.; Su, W. Mechanochemical preparation of kaempferol intermolecular complexes for enhancing the solubility and bioavailability. Drug Dev Ind Pharm 2018, 44 (12), $1924-1932$.

18. Mouhid, L.; Corzo-Martínez, M.; Torres, C.; Vázquez, L.; Reglero, G.; Fornari, T.; Ramírez de Molina, A. Improving in vivo efficacy of bioactive molecules: an overview of potentially antitumor phytochemicals and currently available lipid-based delivery systems. J Oncol 2017, 2017, 7351976.

19. McClements, D. J. Advances in nanoparticle and microparticle delivery systems for increasing the dispersibility, stability, and bioactivity of phytochemicals. Biotechnol Adv 2020, 38, 107287.

20. Subramanian, A.; Jaganathan, S.; Manikandan, A.; Pandiaraj, K.; Gomathi, N.; Supriyanto, E. Recent trends in nano-based drug delivery systems for efficient delivery of phytochemicals in chemotherapy. RSC Adv 2016, 6 (54), 48294-48314.

21. G. Peixoto, M. P.; Treter, J.; de Resende, P. E.; da Silveira, N. P.; Ortega, G. G.; Lawrence, M. J.; Dreiss, C. A. Wormlike micellar aggregates of saponins from ilex paraguariensis a. St. Hil. (mate): A characterisation by cryo-tem, rheology, light scattering and small-angle neutron scattering. J Pharm Sci 2011, 100 (2), 536-546.

22. Kregiel, D.; Berlowska, J.; Witonska, I.; Antolak, H.; Proestos, C.; Babic, M.; Babic, L.; Zhang, B. Saponin-based, biologicalactive surfactants from plants. InTech: 2017, 184-205.

23. Zhao, Q.; Luan, X.; Zheng, M.; Tian, X.-H.; Zhao, J.; Zhang, W.-D.; Ma, B.-L. Synergistic mechanisms of constituents in herbal extracts during intestinal absorption: Focus on natural occurring nanoparticles. Pharmaceutics 2020, 12 (2), 128.

24. Khan, I. A.; Smillie, T. Implementing a "quality by design" approach to assure the safety and integrity of botanical dietary supplements. J Nat Prod 2012, 75 (9), 1665-1673.

25. Newman, D. J.; Cragg, G. M. Natural products as sources of new drugs over the nearly four decades from 01/1981 to 09/2019. J Nat Prod 2020, 83 (3), 770-803.

26. Pubchem. Available online: https://pubchem.ncbi.nlm.nih.gov/ (Accessed on March 2021).

27. Jablonsky, M.; Haz, A.; Burčová, Z.; Kreps, F.; Jablonsky, J. Pharmacokinetic properties of biomass-extracted substances isolated by green solvents. Bioresources 2019, 14, 6294-6303.

28. Chemspider. Available online: http://www.chemspider.com/ (Accessed on March 2021).

29. Acd/labs percepta platform. Available online: https://www.acdlabs.com/products/percepta/index.php (Accessed on March 2021).

30. Epi suit - estimation program interface. Available online: https://www.epa.gov/tsca-screening-tools/epi-suitetm-estimationprogram-interface (Accessed on March 2021).

31. Leong-Skornickova, J.; Šída O.; Wijesundara, S.; Marhold, K. On the identity of turmeric: The typification of curcuma longa 1. (zingiberaceae). Bot J Linn Soc 2008, 157 (1), 37-46.

32. Chatzinasiou, L.; Booker, A.; MacLennan, E.; Mackonochie, M.; Heinrich, M. Turmeric (curcuma longa 1.) products: What quality differences exist? J Herb Med 2019, 17-18, 100281.

33. Rao, P. S.; Ramanjaneyulu, Y. S.; Prisk, V. R.; Schurgers, L. J. A combination of tamarindus indica seeds and curcuma longa rhizome extracts improves knee joint function and alleviates pain in non-arthritic adults following physical activity. Int J Mol Sci 2019, 16 (6), 845-853.

34. Hossain, M. A.; Ishimine, Y. Growth, yield and quality of turmeric (curcuma longa 1.) cultivated on dark-red soil, gray soil and red soil in okinawa, japan. Plant Prod. Sci 2005, 8 (4), 482-486. 
35. Dhakal, S.; Schmidt, W. F.; Kim, M.; Tang, X.; Peng, Y.; Chao, K. Detection of additives and chemical contaminants in turmeric powder using FT-IR spectroscopy. Foods 2019, 8 (5), 143.

36. Amalraj, A.; Pius, A.; Gopi, S.; Gopi, S. Biological activities of curcuminoids, other biomolecules from turmeric and their derivatives - a review. J Tradit Complement Med 2016, 7 (2), 205-233.

37. Czernicka, L.; Grzegorczyk, A.; Marzec, Z.; Antosiewicz, B.; Malm, A.; Kukula-Koch, W. Antimicrobial potential of single metabolites of curcuma longa assessed in the total extract by thin-layer chromatography-based bioautography and image analysis. Int J Mol Sci 2019, 20 (4), 898.

38. Irshad, S.; Muazzam, A.; Shahid, Z.; Dalrymple, M. B. Curcuma longa (turmeric): An auspicious spice for antibacterial, phytochemical and antioxidant activities. Pak J Pharm Sci 2018, 31 (6s), 2689-2696.

39. Choi, Y.; Ban, I.; Lee, H.; Baik, M.-Y.; Kim, W. Puffing as a novel process to enhance the antioxidant and anti-inflammatory properties of curcuma longa 1. (turmeric). Antioxidants 2019, 8 (11), 506.

40. Rodríguez Castaño, P.; Parween, S.; Pandey, A. V. Bioactivity of curcumin on the cytochrome p450 enzymes of the steroidogenic pathway. Int J Mol Sci 2019, 20 (18), 4606.

41. Toden, S.; Theiss, A. L.; Wang, X.; Goel, A. Essential turmeric oils enhance anti-inflammatory efficacy of curcumin in dextran sulfate sodium-induced colitis. Sci Rep 2017, 7 (1), 814.

42. Yu, Y.; Shen, Q.; Lai, Y.; Park, S. Y.; Ou, X.; Lin, D.; Jin, M.; Zhang, W. Anti-inflammatory effects of curcumin in microglial cells. Front Pharmacol 2018, 9 (386).

43. Anand, P.; Kunnumakkara, A. B.; Newman, R. A.; Aggarwal, B. B. Bioavailability of curcumin: Problems and promises. Mol Pharm 2007, 4 (6), 807-818.

44. Chen, Y.; Lu, Y.; Lee, R. J.;Xiang, G. Nano encapsulated curcumin: And its potential for biomedical applications. Int J Nanomed 2020, 15, 3099-3120.

45. Sethiya, A.; Agarwal, D. K.; Agarwal, S. Current trends in drug delivery system of curcumin and its therapeutic applications. Mini Rev Med Chem 2020, 20 (13), 1190-1232.

46. Kim, J. H.; Gupta, S. C.; Park, B.; Yadav, V. R.; Aggarwal, B. B. Turmeric (curcuma longa) inhibits inflammatory nuclear factor (nf)- $\mathrm{kb}$ and $\mathrm{nf}-\mathrm{\kappa b}$-regulated gene products and induces death receptors leading to suppressed proliferation, induced chemosensitization, and suppressed osteoclastogenesis. Mol Nutr Food Res 2012, 56 (3), 454-465.

47. Rizeq, B.; Gupta, I.; Ilesanmi, J.; AlSafran, M.; Rahman, M. D. M.; Ouhtit, A. The power of phytochemicals combination in cancer chemoprevention. J Cancer 2020, 11 (15), 4521-4533.

48. Siviero, A.; Gallo, E.; Maggini, V.; Gori, L.; Mugelli, A.; Firenzuoli, F.; Vannacci, A. Curcumin, a golden spice with a low bioavailability. J Herb Med 2015, 5 (2), 57-70.

49. Kuttan, R.; Bhanumathy, P.; Nirmala, K.; George, M. C. Potential anticancer activity of turmeric (curcuma longa). Cancer Lett 1985, 29 (2), 197-202.

50. Aggarwal, B. B.; Kumar, A.; Bharti, A. C. Anticancer potential of curcumin: Preclinical and clinical studies. Anticancer Res 2003, 23 (1a), 363-398.

51. Kunnumakkara, A. B.; Bordoloi, D.; Harsha, C.; Banik, K.; Gupta, S. C.; Aggarwal, B. B. Curcumin mediates anticancer effects by modulating multiple cell signaling pathways. Clin Sci 2017, 131 (15), 1781-1799.

52. Goel, A.; Kunnumakkara, A. B.; Aggarwal, B. B. Curcumin as "curecumin": From kitchen to clinic. Biochem Pharmacol 2008, 75 (4), 787-809.

53. Li, M.; Yue, G. G.-L.; Tsui, S. K.-W.; Fung, K.-P.; Lau, C. B.-S. Turmeric extract, with absorbable curcumin, has potent antimetastatic effect in vitro and in vivo. Phytomedicine 2018, 46, 131-141.

54. Srivastava, N. S.; Srivastava, R. A. K. Curcumin and quercetin synergistically inhibit cancer cell proliferation in multiple cancer cells and modulate wnt/ $\beta$-catenin signaling and apoptotic pathways in a375 cells. Phytomedicine 2019, 52, 117-128.

55. Almutairi, F. M.; El Rabey, H. A.; Tayel, A. A.; Alalawy, A. I.; Al-Duais, M. A.; Sakran, M. I.; Zidan, N. S. Augmented anticancer activity of curcumin loaded fungal chitosan nanoparticles. Int J Biol Macromol 2020, 155, 861-867.

56. Kasi, P. D.; Tamilselvam, R.; Skalicka-Woźniak, K.; Nabavi, S. F.; Daglia, M.; Bishayee, A.; Pazoki-Toroudi, H.; Nabavi, S. M. Molecular targets of curcumin for cancer therapy: An updated review. Tumour Biol 2016, 37 (10), 13017-13028.

57. Liu, Y.; Sun, H.; Makabel, B.; Cui, Q.; Li, J.; Su, C.; Ashby, C. R., Jr.; Chen, Z.; Zhang, J. The targeting of non-coding rnas by curcumin: Facts and hopes for cancer therapy (review). Oncol Rep 2019, 42 (1), 20-34.

58. Song, X.; Zhang, M.; Dai, E.; Luo, Y. Molecular targets of curcumin in breast cancer (review). Mol Med Rep 2019,19 (1), $23-29$.

59. Wang, H.; Zhang, K.; Liu, J.; Yang, J.; Tian, Y.; Yang, C.; Li, Y.; Shao, M.; Su, W.; Song, N. Curcumin regulates cancer prog ression: Focus on ncrnas and molecular signaling pathways. Front Oncol 2021, 11, 660712.

60. Wang, M.; Jiang, S.; Zhou, L.; Yu, F.; Ding, H.; Li, P.; Zhou, M.; Wang, K. Potential mechanisms of action of curcumin for cancer prevention: Focus on cellular signaling pathways and mirnas. Int J Biol Sci 2019, 15 (6), 1200-1214.

61. Tanvir, E. M.; Hossen, M. S.; Hossain, M. F.; Afroz, R.; Gan, S. H.; Khalil, M. I.; Karim, N. Antioxidant properties of popular turmeric (curcuma longa) varieties from bangladesh. J Food Qual 2017, 8471785.

62. Ak, T.; Gülçin, İ. Antioxidant and radical scavenging properties of curcumin. Chem Biol Interact 2008, 174 (1), $27-37$.

63. Yuliani, S.; Mustofa; Partadiredja, G. Turmeric (curcuma longa 1.) extract may prevent the deterioration of spatial memory and the deficit of estimated total number of hippocampal pyramidal cells of trimethyltin-exposed rats. Drug Chem Toxicol 2018, 41 (1), 62-71. 
64. Hossen, M. S.; Tanvir, E. M.; Prince, M. B.; Paul, S.; Saha, M.; Ali, M. Y.; Gan, S. H.; Khalil, M. I.; Karim, N. Protective mechanism of turmeric (curcuma longa) on carbofuran-induced hematological and hepatic toxicities in a rat model. Pharm Biol 2017, 55 (1), 1937-1945.

65. Praditya, D.; Kirchhoff, L.; Brüning, J.; Rachmawati, H.; Steinmann, J.;Steinmann, E. Anti-infective properties of the golden spice curcumin. Front Microbiol 2019, 10, 912.

66. Jennings, M. R.;Parks, R. J. Curcumin as an antiviral agent. Viruses 2020, 12 (11), 1242.

67. Ou, J. L.; Mizushina, Y.; Wang, S. Y.; Chuang, D. Y.; Nadar, M.; Hsu, W. L. Structure-activity relationship analysis of curcumin analogues on anti-influenza virus activity. FEBS J 2013, 280 (22), 5829-5840.

68. Treml, J.; Gazdová, M.; Šmejkal, K.; Šudomová, M.; Kubatka, P.; Hassan, S. T. S. Natural products-derived chemicals: Breaking barriers to novel anti-hsv drug development. Viruses 2020, 12 (2).

69. Li, Y.; Wang, J.; Liu, Y.; Luo, X.; Lei, W.; Xie, L. Antiviral and virucidal effects of curcumin on transmissible gastroenteritis virus in vitro. J Gen Virol 2020, 101 (10), 1079-1084.

70. Kunnumakkara, A. B.; Rana, V.; Parama, D.; Banik, K.; Girisa, S.; Sahu, H.; Thakur, K. K.; Dutta, U.; Garodia, P.; Gupta, S. C.; Aggarwal, B. B. Covid-19, cytokines, inflammation, and spices: How are they related? Life Sci 2021, 119201.

71. Jurenka, J. S. Anti-inflammatory properties of curcumin, a major constituent of curcuma longa: A review of preclinical and clinical research. Altern Med Rev 2009, 14 (2), 141-153.

72. Lee, S.-Y.; Cho, S.-S.; Li, Y.; Bae, C.-S.; Park, K. M.; Park, D.-H. Anti-inflammatory effect of curcuma longa and allium hookeri co-treatment via nf- $\mathrm{kb}$ and cox-2 pathways. Sci Rep 2020, 10 (1), 5718.

73. Bethapudi, B.; Murugan, S.; Illuri, R.; Mundkinajeddu, D.; Velusami, C. C. Bioactive turmerosaccharides from curcuma longa extract (nr-inf-02): Potential ameliorating effect on osteoarthritis pain. Pharmacogn Mag 2017, 13 (s3), S623-s627.

74. Nicoliche, T.; Maldonado, D. C.; Faber, J.; Silva, M. Evaluation of the articular cartilage in the knees of rats with induced arthritis treated with curcumin. PLOS ONE 2020, 15 (3), e0230228.

75. Jacob, A.; Wu, R.; Zhou, M.; Wang, P. Mechanism of the anti-inflammatory effect of curcumin: PPAR- $\gamma$ activation. PPAR Research 2007, 089369.

76. Bangun, H.; Arianto, A.; Bangun, Y. S.; Nainggolan, M. Antibacterial activity of mucoadhesive gastroretentive drug delivery system of alginate beads containing turmeric extract - pvp solid dispersion. Maced J Med Sci 2019, 7 (22), 3868-3873.

77. Shakeri, A.; Panahi, Y.; Johnston, T. P.; Sahebkar, A. Biological properties of metal complexes of curcumin. Biofactors 2019, 45 (3), 304-317.

78. Chen, C.; Long, L.; Zhang, F.; Chen, Q.; Chen, C.; Yu, X.; Liu, Q.; Bao, J.;Long, Z. Antifungal activity, main active components and mechanism of curcuma longa extract against fusarium graminearum. PLoS One 2018, 13 (3), e0194284.

79. Murugesh, J.; Annigeri, R. G.; Mangala, G. K.; Mythily, P. H.; Chandrakala, J. Evaluation of the antifungal efficacy of different concentrations of curcuma longa on candida albicans: An in vitro study. JOMFP 2019, 23 (2), 305-305.

80. Jamali, N.; Adib-Hajbaghery, M.; Soleimani, A. The effect of curcumin ointment on knee pain in older adults with osteoarthritis: A randomized placebo trial. BMC Complement Med Ther 2020, 20 (1), 305.

81. Park, M. J.; Moon, S. J.; Lee, S. H.; Yang, E. J.; Min, J. K.; Cho, S. G.; Yang, C. W.; Park, S. H.; Kim, H. Y.; Cho, M. L. Curcumin attenuates acute graft-versus-host disease severity via in vivo regulations on th1, th17 and regulatory t cells. PLoS One 2013, 8 (6), e67171.

82. Jiang, Z.; Wan, Y.; Li, P.; Xue, Y.; Cui, W.; Chen, Q.; Chen, J.; Wang, F.; Mao, D. Effect of curcumin supplement in summer diet on blood metabolites, antioxidant status, immune response, and testicular gene expression in hu sheep. Animals 2019, 9 (10).

83. Abdollahi, E.; Momtazi, A. A.; Johnston, T. P.; Sahebkar, A. Therapeutic effects of curcumin in inflammatory and immunemediated diseases: A nature-made jack-of-all-trades?. J Cell Physiol 2018, 233 (2), 830-848.

84. Gupta, S. C.; Patchva, S.; Aggarwal, B. B. Therapeutic roles of curcumin: Lessons learned from clinical trials. The AAPS journal 2013, 15 (1), 195-218.

85. Asher, G. N.; Spelman, K. Clinical utility of curcumin extract. Altern Ther Health Med 2013, 19 (2), 20-22.

86. Khajehdehi, P. Turmeric: Reemerging of a neglected asian traditional remedy. J Nephropathol 2012, 1 (1), 17-22.

87. Heck, A. M.; DeWitt, B. A.; Lukes, A. L. Potential interactions between alternative therapies and warfarin. Am J Health Syst Pharm 2000, 57 (13), 1228-1230.

88. Ghorbani, Z.; Hekmatdoost, A.; Mirmiran, P. Anti-hyperglycemic and insulin sensitizer effects of turmeric and its principle constituent curcumin. Int J Endocrinol Metab 2014, 12 (4), e18081-e18081.

89. Jiao, Y.; Wilkinson, J. t.; Di, X.; Wang, W.; Hatcher, H.; Kock, N. D.; D'Agostino, R., Jr.; Knovich, M. A.; Torti, F. M.; Torti, S. V. Curcumin, a cancer chemopreventive and chemotherapeutic agent, is a biologically active iron chelator. Blood 2009, 113 (2), 462-469.

90. Allium sativum. Available online: https://ngpherbaria.org/portal/taxa/index.php?taxon=71501\&cl=VPlants (Accessed on April 2021).

91. Garlic, allium sativum. Available online: https://hort.extension.wisc.edu/articles/garlic-allium-sativum/ (Accessed on April 2021).

92. Mikaili, P.; Maadirad, S.; Moloudizargari, M.; Aghajanshakeri, S.; Sarahroodi, S. Therapeutic uses and pharmacological properties of garlic, shallot, and their biologically active compounds. Iran J Basic Med Sci 2013, 16 (10), 1031-1048.

93. Bayan, L.; Koulivand, P. H.; Gorji, A. Garlic: A review of potential therapeutic effects. Avicenna J Phytomed. 2014, 4 (1), 1-14.

94. Block, E. Garlic and other alliums: The lore and the science. 1rst ed. Royal Society of Chemistry: 2010.

95. Rivlin, R. S. Historical perspective on the use of garlic. J Nutr 2001, 131 (3), 951S-954S. 
96. Divya, B. J.; Suman, B.; Venkataswamy, M.; Thyagaraju, K. A study on phytochemicals, functional groups and mineral composition of allium sativum (garlic) cloves. Int J Curr Pharm Res 2017, 9 (3), 42-45.

97. Saif, S.; Hanif, M. A.; Rehman, R.; Riaz, M. Chapter 23 - garlic. In Medicinal Plants of South Asia, Hanif, M. A.; Nawaz, H.; Khan, M. M.; Byrne, H. J., Eds. Elsevier: 2020; 301-315.

98. El-Saber Batiha, G.; Magdy Beshbishy, A.; G Wasef, L.; Elewa, Y. H. A.; A Al-Sagan, A.; Abd El-Hack, M. E.; Taha, A. E.; M Abd-Elhakim, Y.; Prasad Devkota, H. Chemical constituents and pharmacological activities of garlic (allium sativum 1.): A review. Nutrients 2020, 12 (3), 872.

99. Shang, A.; Cao, S.-Y.; Xu, X.-Y.; Gan, R.-Y.; Tang, G.-Y.; Corke, H.; Mavumengwana, V.; Li, H.-B. Bioactive compounds and biological functions of garlic (allium sativum 1.). Foods 2019, 8 (7), 246.

100. Borlinghaus, J.; Albrecht, F.; Gruhlke, M. C. H.; Nwachukwu, I. D.; Slusarenko, A. J. Allicin: Chemistry and biological properties. Molecules 2014, 19 (8), 12591-12618.

101. Amagase, H.; Petesch, B. L.; Matsuura, H.; Kasuga, S.; Itakura, Y. Intake of garlic and its bioactive components. J Nutr 2001, 131 (3), 955S-962S.

102. Lawson, L. D.; Hunsaker, S. M. Allicin bioavailability and bioequivalence from garlic supplements and garlic foods. Nutrients 2018, 10 (7), 812.

103. Kaschula, C. H.; Hunter, R.; Cotton, J.; Tuveri, R.; Ngarande, E.; Dzobo, K.; Schäfer, G.; Siyo, V.; Lang, D.; Kusza, D. A.; Davies, B.; Katz, A. A.; Parker, M. I. The garlic compound ajoene targets protein folding in the endoplasmic reticulum of cancer cells. Mol Carcinog 2016, 55 (8), 1213-1228.

104. Torres-Palazzolo, C.; de Paola, M.; Quesada, I.; Camargo, A.; Castro, C. 2-vinyl-4h-1,3-dithiin, a bioavailable compound from garlic, inhibits vascular smooth muscle cells proliferation and migration by reducing oxidative stress. Plant Foods Hum Nutr 2020, 75 (3), 355-361.

105. Wang, H. C.; Yang, J. H.; Hsieh, S. C.; Sheen, L. Y. Allyl sulfides inhibit cell growth of skin cancer cells through induction of DNA damage mediated g2/m arrest and apoptosis. J Agric Food Chem 2010, 58 (11), 7096-7103.

106. Țigu, A. B.; Toma, V.-A.; Moț, A. C.; Jurj, A.; Moldovan, C. S.; Fischer-Fodor, E.; Berindan-Neagoe, I.; Pârvu, M. The synergistic antitumor effect of 5-fluorouracil combined with allicin against lung and colorectal carcinoma cells. Molecules 2020,25 (8), 1947.

107. Petrovic, V.; Nepal, A.; Olaisen, C.; Bachke, S.; Hira, J.; Søgaard, C. K.; Røst, L. M.; Misund, K.; Andreassen, T.; Melø, T. M.; Bartsova, Z.; Bruheim, P.; Otterlei, M. Anti-cancer potential of homemade fresh garlic extract is related to increased endoplasmic reticulum stress. Nutrients 2018, 10 (4), 450.

108. Tanaka, S.; Haruma, K.; Kunihiro, M.; Nagata, S.; Kitadai, Y.; Manabe, N.; Sumii, M.; Yoshihara, M.; Kajiyama, G.; Chayama, K. Effects of aged garlic extract (age) on colorectal adenomas: A double-blinded study. Hiroshima J Med Sci 2004, 53 (3-4), 3945.

109. Zhou, X.; Qian, H.; Zhang, D.;Zeng, L. Garlic intake and the risk of colorectal cancer: A meta-analysis. Medicine 2020, 99 (1), e18575.

110. Fleischauer, A. T.; Poole, C.; Arab, L. Garlic consumption and cancer prevention: Meta-analyses of colorectal and stomach cancers. Am J Clin Nutr 2000, 72 (4), 1047-1052.

111. Chiavarini, M.; Minelli, L.; Fabiani, R. Garlic consumption and colorectal cancer risk in man: A systematic review and metaanalysis. Public Health Nutr 2016, 19 (2), 308-317.

112. Bhatt, A.; Patel, V. Antioxidant activity of garlic using conventional extraction and in vitro gastrointestinal digestion. Free Radic Antioxid 2013, 3 (1), 30-34.

113. Lei, M.-M.; Xu, M.-Y.; Zhang, Z.-S.; Zhang, M.; Gao, Y. The analysis of saccharide in black garlic and its antioxidant activity.

Adv J Food Sci Technol 2014, 6 (6), 755-760.

114. Moosavian, S. P.; Paknahad, Z.; Habibagahi, Z. A randomized, double-blind, placebo-controlled clinical trial, evaluating the garlic supplement effects on some serum biomarkers of oxidative stress, and quality of life in women with rheumatoid arthritis. Int J Clin Pract 2020, 74 (7), e13498.

115. Rouf, R.; Uddin, S. J.; Sarker, D. K.; Islam, M. T.; Ali, E. S.; Shilpi, J. A.; Nahar, L.; Tiralongo, E.; Sarker, S. D. Antiviral potential of garlic (allium sativum) and its organosulfur compounds: A systematic update of pre-clinical and clinical data. Trends Food Sci E Technol 2020, 104, 219-234.

116. Khanal, S.; Ghimire, P.; Dhamoon, A. S. The repertoire of adenovirus in human disease: The innocuous to the deadly. Biomed 2018, $6(1), 30$.

117. Mehrbod, P.; Aini, I.; Amini, E.; Eslami, M.; Torabi, A.; Bande, F.; Kheiri, M. T. Assessment of direct immunofluorescence assay in detection of antiviral effect of garlic extract on influenza virus. Afr J Microbiol Res 2013, 7 (21), 2608-2612.

118. Alejandria, MM. Dengue haemorrhagic fever or dengue shock syndrome in children. BMJ Clin Evid 2015, $2015,0917$.

119. Straface, G.; Selmin, A.; Zanardo, V.; De Santis, M.; Ercoli, A.; Scambia, G. Herpes simplex virus infection in pregnancy. Infect Dis Obstet Gynecol. 2012, 2012: 385697.

120. Chavan, R. D.; Shinde, P.; Girkar, K.; Madage, R.; Chowdhary, A. Assessment of anti-influenza activity and hemagglutination inhibition of plumbago indica and allium sativum extracts. Pharmacog Res 2016, 8 (2), 105.

121. Klenk, H.-D.; Matrosovich, M.;Stech, J. Avian influenza: Molecular mechanisms of pathogenesis and host range. Caister Academic Press: 2008, 253-301.

122. Matheny, S. C.; Kingery, J. E. Hepatitis A. Am Fam Physician 2012, 86(11), 1027-1012.

123. Wang, L.; Jiao, H.; Zhao, J.; Wang, X.; Sun, S.; Lin, H. Allicin alleviates reticuloendotheliosis virus-induced immunosuppression via erk/mitogen-activated protein kinase pathway in specific pathogen-free chickens. Front Immunol 2017, 8, 1856. 
124. Vlasova, A. N.; Amimo, J. O.; Saif, L. Porcine rotaviruses: Epidemiology, immune responses and control strategies. Viruses 2017, 9 (3), 48.

125. Thuy, B.; My, T.; Hai, N.; Hieu, L.; Hoa, T.; Thi Phuong Loan, H.; Triet, N.; Anh, T.; Quy, P; Tat, P.; Hue, N.; Quang, D.; Trung, N.; Tung, V.; Huynh, L.; Nhung, N. Investigation into SARS-CoV-2 resistance of compounds in garlic essential oil. ACS Omega 2020, $5(14), 8312-8320$.

126. Lee, D. Y.; Li, H.; Lim, H. J.; Lee, H. J.; Jeon, R.; Ryu, J.-H. Anti-inflammatory activity of sulfur-containing compounds from garlic. J Med Food 2012, 15 (11), 992-999.

127. Metwally, D. M.; Al-Olayan, E. M.; Alanazi, M.; Alzahrany, S. B.; Semlali, A. Antischistosomal and anti-inflammatory activity of garlic and allicin compared with that of praziquantel in vivo. BMC Complement Altern Med 2018, 18 (1), 135-135.

128. Zare, E.; Alirezaei, A.; Bakhtiyari, M.; Mansouri, A. Evaluating the effect of garlic extract on serum inflammatory markers of peritoneal dialysis patients: A randomized double-blind clinical trial study. BMC Nephrol 2019, 20 (1), 26-26.

129. Yadav, S.; Trivedi, N. A.; Bhatt, J. D. Antimicrobial activity of fresh garlic juice: An in vitro study. Ayu 2015, 36 (2), $203-207$.

130. Venâncio, P. C.; Raimundo Figueroba, S.; Dias Nani, B.; Eduardo Nunes Ferreira, L.; Vilela Muniz, B.; de Sá Del Fiol, F.; Sartoratto, A.; Antonio Ribeiro Rosa, E.; Carlos Groppo, F. Antimicrobial activity of two garlic species (allium sativum and a. Tuberosum) against staphylococci infection. In vivo study in rats. Adv Pharm Bull 2017, 7 (1), 115-121.

131. Farrag, H. A.; Hosny, A.; Hawas, A. M.; Hagras, S. A. A.; Helmy, O. M. Potential efficacy of garlic lock therapy in combating biofilm and catheter-associated infections; experimental studies on an animal model with focus on toxicological aspects. Saudi Pharm J 2019, 27 (6), 830-840.

132. Zardast, M.; Namakin, K.; Esmaelian Kaho, J.; Hashemi, S. S. Assessment of antibacterial effect of garlic in patients infected with helicobacter pylori using urease breath test. Avicenna J Phytomed 2016, 6 (5), 495-501.

133. Li, W. R.; Shi, Q. S.; Dai, H. Q.; Liang, Q.; Xie, X. B.; Huang, X. M.; Zhao, G. Z.; Zhang, L. X. Antifungal activity, kinetics and molecular mechanism of action of garlic oil against candida albicans. Sci Rep 2016, 6, 22805.

134. Aala, F.; Yusuf, U. K.; Nulit, R.; Rezaie, S. Inhibitory effect of allicin and garlic extracts on growth of cultured hyphae. Iran J Basic Med Sci 2014, 17 (3), 150-154.

135. Li, W. R.; Shi, Q. S.; Liang, Q.; Huang, X. M.; Chen, Y. B. Antifungal effect and mechanism of garlic oil on penicillium funiculosum. Appl Microbiol Biotechnol 2014, 98 (19), 8337-8346.

136. Feng, Y.; Zhu, X.; Wang, Q.; Jiang, Y.; Shang, H.; Cui, L.; Cao, Y. Allicin enhances host pro-inflammatory immune responses and protects against acute murine malaria infection. Malaria Journal 2012, 11, 268-268.

137. Bruck, R.; Aeed, H.; Brazovsky, E.; Noor, T.; Hershkoviz, R. Allicin, the active component of garlic, prevents immune-mediated, concanavalin a-induced hepatic injury in mice. Liver Int 2005, 25 (3), 613-621.

138. Xu, C.; Mathews, A. E.; Rodrigues, C.; Eudy, B. J.; Rowe, C. A.; O'Donoughue, A.; Percival, S. S. Aged garlic extract supplementation modifies inflammation and immunity of adults with obesity: A randomized, double-blind, placebo-controlled clinical trial. Clin Nutr ESPEN 2018, 24, 148-155.

139. Nantz, M. P.; Rowe, C. A.; Muller, C. E.; Creasy, R. A.; Stanilka, J. M.;Percival, S. S. Supplementation with aged garlic extract improves both $\mathrm{nk}$ and $\gamma \delta$-t cell function and reduces the severity of cold and flu symptoms: A randomized, double-blind, placebo-controlled nutrition intervention. Clin Nutr 2012, 31 (3), 337-344.

140. Shaikh, S. A.; Tischer, S.; Choi, E. K.; Fontana, R. J. Good for the lung but bad for the liver? Garlic-induced hepatotoxicity following liver transplantation. J Clin Pharm Ther 2017, 42 (5), 646-648.

141. Hoshino, T.; Kashimoto, N.; Kasuga, S. Effects of garlic preparations on the gastrointestinal mucosa. J Nutr 2001, 131 (3s), $1109 \mathrm{~s}-$ 1113s.

142. Suzuki, Y.; Saito, J.; Misa, K.; Fukuhara, N.; Fukuhara, A.; Munakata, M. A case of black garlic-induced pneumonia as an adverse reaction. Allergol Int 2016, 65 (3), 353-355.

143. Garlic. Available online: https://www.nccih.nih.gov/health/garlic (Accessed on April 2021).

144. Barceloux, D. G. Cinnamon (cinnamomum species). Dis Mon 2009, 55 (6), 327-35.

145. Thomas, J.;Kuruvilla, K., Cinnamon. In Handbook of Herbs and Spices, Elsevier: 2012; 182-196.

146. Ramazani, E.; YazdFazeli, M.; Emami, S. A.; Mohtashami, L.; Javadi, B.; Asili, J.; Tayarani-Najaran, Z. Protective effects of cinnamomum verum, cinnamomum cassia and cinnamaldehyde against 6-ohda-induced apoptosis in pc12 cells. Mol Biol Rep 2020, 47 (4), 2437-2445.

147. Alizadeh Behbahani, B.; Falah, F.; Lavi Arab, F.; Vasiee, M.; Tabatabaee Yazdi, F. Chemical composition and antioxidant, antimicrobial, and antiproliferative activities of cinnamomum zeylanicum bark essential oil. Evid-Based Complement Altern Med 2020, 2020, 5190603.

148. Rao, P. V.; Gan, S. H. Cinnamon: A multifaceted medicinal plant. Evid-Based Complement Altern. Med $2014,642942$.

149. Ananthakrishnan, R.; Chandra, P.; Kumar, B.; Rameshkumar, K. B. Quantification of coumarin and related phenolics in cinnamon samples from south india using UPLC-ESI-QQQLIT-MS/MS method. Int. J. Food Prop 2018, 21 (1), 50-57.

150. Khuwijitjaru, P.; Sayputikasikorn, N.; Samuhasaneetoo, S.; Penroj, P.; Siriwongwilaichat, P.; Adachi, S. Subcritical water extraction of flavoring and phenolic compounds from cinnamon bark (cinnamomum zeylanicum). J Oleo Sci 2012, 61 (6), $349-355$.

151. Klejdus, B.; Kováčik, J. Quantification of phenols in cinnamon: A special focus on "total phenols" and phenolic acids including desi-orbitrap MS detection. Ind Crop Prod 2016, 83, 774-780.

152. Yang, X. Q.; Zheng, H.; Ye, Q.; Li, R. Y.; Chen, Y. Essential oil of cinnamon exerts anti-cancer activity against head and neck squamous cell carcinoma via attenuating epidermal growth factor receptor - tyrosine kinase. J Buon 2015, 20 (6), 1518-1525. 
153. Koppikar, S. J.; Choudhari, A. S.; Suryavanshi, S. A.; Kumari, S.; Chattopadhyay, S.; Kaul-Ghanekar, R. Aqueous cinnamon extract (ace-c) from the bark of cinnamomum cassia causes apoptosis in human cervical cancer cell line (siha) through loss of mitochondrial membrane potential. BMC cancer 2010, 10, 210-210.

154. Perng, D. S.; Tsai, Y. H.; Cherng, J.; Wang, J. S.; Chou, K. S.; Shih, C. W.; Cherng, J. M. Discovery of a novel anticancer agent with both anti-topoisomerase $\mathrm{i}$ and ii activities in hepatocellular carcinoma sk-hep-1 cells in vitro and in vivo: Cinnamomum verum component 2-methoxycinnamaldehyde. Drug Des Devel Ther 2016, 10, 141-153.

155. Mateen, S.; Rehman, M. T.; Shahzad, S.; Naeem, S. S.; Faizy, A. F.; Khan, A. Q.; Khan, M. S.; Husain, F. M.; Moin, S. Antioxidant and anti-inflammatory effects of cinnamaldehyde and eugenol on mononuclear cells of rheumatoid arthritis patients. Eur J Pharmacol 2019, 852, 14-24.

156. Davaatseren, M.; Jo, Y.-J.; Hong, G.-P.; Hur, H. J.; Park, S.; Choi, M.-J. Studies on the anti-oxidative function of trans-cinnamaldehyde-included $\beta$-cyclodextrin complex. Molecules 2017, 22 (12), 1868.

157. Borzoei, A.; Rafraf, M.; Niromanesh, S.; Farzadi, L.; Narimani, F.; Doostan, F. Effects of cinnamon supplementation on antioxidant status and serum lipids in women with polycystic ovary syndrome. J Tradit Complement Med 2018, 8 (1), 128-133.

158. Setzer, W. Essential oils as complementary and alternative medicines for the treatment of influenza. Am J Essent Oil Nat Prod 2016, 4 (4), 16-22.

159. Moshaverinia, M.; Rastegarfar, M.; Moattari, A.; Lavaee, F. Evaluation of the effect of hydro alcoholic extract of cinnamon on herpes simplex virus-1. Dent Res J 2020, 17 (2), 114-119.

160. Kulkarni, S. A.; Nagarajan, S. K.; Ramesh, V.; Palaniyandi, V.; Selvam, S. P.; Madhavan, T. Computational evaluation of major components from plant essential oils as potent inhibitors of SARS-CoV-2 spike protein. J Mol Struct 2020, 1221, 128823-128823.

161. Han, X.; Parker, T. L. Antiinflammatory activity of cinnamon (cinnamomum zeylanicum) bark essential oil in a human skin disease model. Phytother Res 2017, 31 (7), 1034-1038.

162. Hagenlocher, Y.; Satzinger, S.; Civelek, M.; Feilhauer, K.; Köninger, J.; Bischoff, S. C.; Lorentz, A. Cinnamon reduces inflammatory response in intestinal fibroblasts in vitro and in colitis in vivo leading to decreased fibrosis. Mol Nutr Food Res 2017, 61 (9), 1601085.

163. Ahmed, H. M.; Ramadhani, A. M.; Erwa, I. Y.; Ishag, O. A. O.; Saeed, M. B. Chemistry, A. Phytochemical screening, chemical composition and antimicrobial activity of cinnamon verum bark. Int Res J Pure Appl Chem 2020, 36-43.

164. Faikoh, E. N.; Hong, Y.-H.; Hu, S.-Y. Liposome-encapsulated cinnamaldehyde enhances zebrafish (danio rerio) immunity and survival when challenged with vibrio vulnificus and streptococcus agalactiae. Fish Shellfish Immunol 2014, 38 (1), 15-24.

165. Kowalska, J.; Tyburski, J.; Krzymińska, J.; Jakubowska, M. Cinnamon powder: An in vitro and in vivo evaluation of antifungal and plant growth promoting activity. Eur J Plant Pathol 2020, 156 (1), 237-243.

166. Wang, G. S.; Deng, J. H.; Ma, Y. H.; Shi, M.;Li, B. Mechanisms, clinically curative effects, and antifungal activities of cinnamon oil and pogostemon oil complex against three species of candida. J Tradit Chin Med 2012, 32 (1), 19-24.

167. Ayatollahi Mousavi, S. A.; Kazemi, A. In vitro and in vivo antidermatophytic activities of some iranian medicinal plants. Med Mycol 2015, 53 (8), 852-9.

168. Hagenlocher, Y.; Kiessling, K.; Schäffer, M.; Bischoff, S. C.;Lorentz, A. Cinnamaldehyde is the main mediator of cinnamon extract in mast cell inhibition. Eur J Nutr 2015, 54 (8), 1297-1309.

169. Ose, R.; Tu, J.; Schink, A.; Maxeiner, J.; Schuster, P.; Lucas, K.; Saloga, J.; Bellinghausen, I. Cinnamon extract inhibits allergenspecific immune responses in human and murine allergy models. Clin Exp Allergy 2020, 50 (1), 41-50.

170. Grant-Alfieri, A.; Schaechter, J.; Lipshultz, S. E. Ingesting and aspirating dry cinnamon by children and adolescents: The "cinnamon challenge". Pediatrics 2013, 131 (5), 833-835.

171. Roth-Walter, F.; Moskovskich, A.; Gomez-Casado, C.; Diaz-Perales, A.; Oida, K.; Singer, J.; Kinaciyan, T.; Fuchs, H. C.; JensenJarolim, E. Immune suppressive effect of cinnamaldehyde due to inhibition of proliferation and induction of apoptosis in immune cells: Implications in cancer. PLoS One 2014, 9 (10), e108402.

172. Ernst, E. Herbal medicinal products during pregnancy: Are they safe? Bjog 2002, 109 (3), 227-35.

173. Hsieh, C. J.; Sun, M.; Osborne, G.; Ricker, K.; Tsai, F. C.; Li, K.; Tomar, R.; Phuong, J.; Schmitz, R.; Sandy, M. S. Cancer hazard identification integrating human variability: The case of coumarin. Int J Toxicol 2019, 38 (6), 501-552.

174. Rethinam, P.; Sundararaj, P. Annona muricata l., soursop (graviola)-nature's gift to mankind with amazing medicinal benefits. Inter J Inno Horticult 2016, 5 (2), 73-80.

175. Chatrou, L. W.; Pirie, M. D.; Erkens, R. H. J.; Couvreur, T. L. P.; Neubig, K. M.; Abbott, J. R.; Mols, J. B.; Maas, J. W.; Saunders, R. M. K.;Chase, M. W. A new subfamilial and tribal classification of the pantropical flowering plant family annonaceae informed by molecular phylogenetics. Bot J Linnean Soc 2012, 169 (1), 5-40.

176. Coria-Téllez, A. V.; Montalvo-Gónzalez, E.; Yahia, E. M.; Obledo-Vázquez, E. N. Annona muricata: A comprehensive review on its traditional medicinal uses, phytochemicals, pharmacological activities, mechanisms of action and toxicity. Arab J Chem 2018, 11 (5), 662-691.

177. Annona muricata 1. Available online: https://www.tandfonline.com/doi/full/10.1080/10942912.2018. (Accessed on March 2021).

178. Agu, K. C.; Okolie, P. N. Proximate composition, phytochemical analysis, and in vitro antioxidant potentials of extracts of annona muricata (soursop). Food Sci E Nut 2017, 5 (5), 1029-1036.

179. Viraraghavan S, S. N. Phytochemical screening of hydroalcoohol fruit extract of annona muricata. Int J Adv Res Devel 2018, 3 (1), 681-685.

180. Anaya Esparza, L. M.; Montalvo-González, E., Bioactive compounds of soursop (annona muricata 1.) fruit. In Bioactive compounds in underutilized fruits and nuts, Murthy, H. N.; Bapat, V. A., Eds. Springer International Publishing: Cham, 2020; 175-189. 
181. Rady, I.; Bloch, M. B.; Chamcheu, R.-C. N.; Banang Mbeumi, S.; Anwar, M. R.; Mohamed, H.; Babatunde, A. S.; Kuiate, J.-R.; Noubissi, F. K.; El Sayed, K. A.; Whitfield, G. K.; Chamcheu, J. C. Anticancer properties of graviola (annona muricata): A comprehensive mechanistic review. Oxid Med Cell Longev 2018, 1826170.

182. Simpson, D.; Amos, S., Chapter 12 - other plant metabolites. In Pharmacognosy, Badal, S.; Delgoda, R., Eds. Academic Press: Boston, 2017; 267-280.

183. Jan, A. T.; Kamli, M. R.; Murtaza, I.; Singh, J. B.; Ali, A.; Haq, Q. M. R. Dietary flavonoid quercetin and associated health benefits - an overview. Food Rev Int 2010, 26 (3), 302-317.

184. Kahkeshani, N.; Farzaei, F.; Fotouhi, M.; Alavi, S. S.; Bahramsoltani, R.; Naseri, R.; Momtaz, S.; Abbasabadi, Z.; Rahimi, R.; Farzaei, M. H.; Bishayee, A. Pharmacological effects of gallic acid in health and diseases: A mechanistic review. Iran J Basic Med Sci 2019, 22 (3), 225-237.

185. Seo, D. J.;Choi, C., Chapter 25 - viral disease and use of polyphenolic compounds. In Polyphenols: Prevention and treatment of human disease (second edition), Watson, R. R.; Preedy, V. R.; Zibadi, S., Eds. Academic Press: 2018; 301-312.

186. Enweani, I.; Obroku, J.; Enahoro, T.; Omoifo, C. The biochemical analysis of soursop (annona muricata 1.) and sweetsop (a.Squamosa 1.) and their potential use as oral rehydration therapy. J Food Agri Environ 2004, 22, 39-43.

187. Gyesi, J.; Opoku, R.; Borquaye, L. Chemical composition, total phenolic content, and antioxidant activities of the essential oils of the leaves and fruit pulp of annona muricata l.(soursop) from ghana. Biochem Res Int. 2019: 4164576.

188. Cassé, C. Molecular mechanisms of annona muricata anti-proliferative/anti-cancer properties. Biomed Genetics Genomics 2018, $4(1), 1-4$.

189. Deep, G.; Kumar, R.; Jain, A. K.; Dhar, D.; Panigrahi, G. K.; Hussain, A.; Agarwal, C.; El-Elimat, T.; Sica, V. P.; Oberlies, N. H.;Agarwal, R. Graviola inhibits hypoxia-induced NADPH oxidase activity in prostate cancer cells reducing their proliferation and clonogenicity. Sci Rep 2016, 6, 23135.

190. Qazi, A. K.; Siddiqui, J. A.; Jahan, R.; Chaudhary, S.; Walker, L. A.; Sayed, Z.; Jones, D. T.; Batra, S. K.; Macha, M. A. Emerging therapeutic potential of graviola and its constituents in cancers. Carcinogenesis 2018, 39 (4), 522-533.

191. McLaughlin, J. L. Paw paw and cancer: Annonaceous acetogenins from discovery to commercial products. J Nat Prod 2008, 71 (7), 1311-1321.

192. Torres, M. P.; Rachagani, S.; Purohit, V.; Pandey, P.; Joshi, S.; Moore, E. D.; Johansson, S. L.; Singh, P. K.; Ganti, A. K.;Batra, S. K. Graviola: A novel promising natural-derived drug that inhibits tumorigenicity and metastasis of pancreatic cancer cells in vitro and in vivo through altering cell metabolism. Cancer letters 2012, 323 (1), 29-40.

193. Yap, C. V.; Subramaniam, K. S.; Khor, S. W.; Chung, I. Annonacin exerts antitumor activity through induction of apoptosis and extracellular signal-regulated kinase inhibition. Pharmacog Res 2017, 9 (4), 378-383.

194. Yiallouris, A.; Patrikios, I.; Johnson, E. O.; Sereti, E.; Dimas, K.; De Ford, C.; Fedosova, N. U.; Graier, W. F.; Sokratous, K.; Kyriakou, K.; Stephanou, A. Annonacin promotes selective cancer cell death via nka-dependent and serca-dependent pathways. Cell Death Dis 2018, 9 (7), 764.

195. Byun, E.-B.; Song, H.-Y.; Kim, W. S. Polysaccharides from annona muricata leaves protect normal human epidermal keratinocytes and mice skin from radiation-induced injuries. Rad Phys Chem 2020, 170, 108672.

196. George, V. C.; Kumar, D.; Rajkumar, V.; Suresh, P.; Kumar, R. A. Quantitative assessment of the relative antineoplastic potential of the n-butanolic leaf extract of annona muricata linn. In normal and immortalized human cell lines. Asian Pac J Cancer Prev 2012, 13 (2), 699-704.

197. Zamudio-Cuevas, Y.; Díaz-Sobac, R.; Vázquez-Luna, A.; Landa-Solís, C.; Cruz-Ramos, M.; Santamaría-Olmedo, M.; MartínezFlores, K.; Fuentes-Gómez, A. J.; López-Reyes, A. The antioxidant activity of soursop decreases the expression of a member of the nadph oxidase family. Food Funct 2014, 5 (2), 303-309.

198. Baskar, R.; Rajeswari, V.; Kumar, T. S. In vitro antioxidant studies in leaves of annona species. Indian J Exp Biol 2007, 45 (5), 480-485.

199. Biba, V.; Amily, A.; Sangeetha, S.; Remani, P. Anticancer, antioxidant and antimicrobial activity of annonaceae family. World J Pharm Pharm Sc 2014, 3, 1595-1604.

200. Padma, P.; Pramod, N. P.; Thyagarajan, S. P.; Khosa, R. L. Effect of the extract of annona muricata and petunia nyctaginiflora on herpes simplex virus. J Ethnopharmacol 1998, 61 (1), 81-83.

201. Wahab, N.Z.A.; Ibrahim, N.; Kamarudin, M.K.A.; Lananan, F.; Juahir, H.; Ghazali, A.; Ireana Yusra, A.F. Cytotoxicity and antiviral activity of annona muricata aqueous leaves extract against dengue virus type 2. J Fundam Appl Sci 2018, 10 (1S), 580589.

202. Le Donne, M.; Lentini, M.; Alibrandi, A.; Salimbeni, V.; Giuffre, G.; Mazzeo, F.; Triolo, O.; D'Anna, R. Antiviral activity of ellagic acid and annona muricata in cervical hpv related pre-neoplastic lesions: A randomized trial. J Funct Foods 2017, 35, 549554.

203. Ahmed, M. Natural compounds from djiboutian medicinal plants as inhibitors of COVID-19 by in silico investigations. ChemRxiv 2020 (1).

204. Jianfeng, Y.; Shengxi, S.; Bin, L.; Zhihao, W.; Yi-Zhou, J.; Yunqing, L.; Feng, C.; Bing, L. Emergency antiviral drug discovery during a pandemic-a case study on the application of natural compounds to treat covid-19. ChemiRxiv 2020 (1).

205. Abdul Wahab, S. M.; Jantan, I.; Haque, M. A.; Arshad, L. Exploring the leaves of annona muricata 1. As a source of potential anti-inflammatory and anticancer agents. Front Pharmacol 2018, 9, 661.

206. Cercato, L. M.; Araújo, J. M. D.; Oliveira, A. S.; Melo, A. J. O.; Lima, B. S.; dos Santos, E. W. P.; Dos S. Neto, A. G.; De Albuquerque-Júnior, R. L. C.; Duarte, M. C.; Araujo, A. A. S.; Silva, A. M. O.; Grespan, R.; Correa, C. B.; Camargo, E. A. Reduced 
cutaneous inflammation associated with antioxidant action after topical application of the aqueous extract of annona muricata leaves. Inflammopharmacology 2021, 29 (1), 307-315.

207. Laksmitawati, D.; Prasanti, A.; Larasinta, N.; Syauta, G.; Hilda, R.; Ramadaniati, H.; Widyastuti, A.; Karami, N.; Afni, M.; Rihibiha, D.; Kusuma, H.; Widowati, W. Anti-inflammatory potential of gandarusa (gendarussa vulgaris nees) and soursoup (annona muricata 1) extracts in lps stimulated-macrophage cell (raw264.7). J Nat Med 2016, 16, 73-81.

208. Choi, M.; Kang, Y.-R.; Zu, H. D.; Lim, I.-S.; Jung, S. K.; Chang, Y. H. Effects of time on phenolics and in vitro bioactivity in autoclave extraction of graviola (annona muricata) leaf. Biotechnol Bioprocess Eng 2020, 25 (1), 9-15.

209. Ishola, I. O.; Awodele, O.; Olusayero, A. M.; Ochieng, C. O. Mechanisms of analgesic and anti-inflammatory properties of annona muricata linn. (annonaceae) fruit extract in rodents. J Med Food 2014, 17 (12), 1375-1382.

210. Pai, B. M.; Rajesh, G.; Shenoy, R.; Rao, A. Anti-microbial efficacy of soursop leaf extract (annona muricata) on oral pathogens: An in-vitro study. JCDR 2016, 10 (11), ZC01-ZC04.

211. Rodriguez-Perez, J. L.; Millones-Gomez, P. A. Antibacterial effect of annona muricata 1. Leaves on streptococcus mutans atcc 25175 strains. J Clin Diag Res 2019, 13 (10).

212. Oluyemi Dada, E.; Sunday Faleye, O. In-vitro and in-vivo activities of the ethanol pulp extract of annona muricata (linn) fruit in albino rats infected with salmonella typhi. J Adv Med Pharm Sci 2016, 5(4), 1-12.

213. Iyanda-Joel, W. O.; Omonigbehin, E. A.; Iweala, E. E. J.; Chinedu, S. N. Antibacterial studies on fruit-skin and leaf extracts of annona muricata in ota, nigeria. IOP Conf Ser Earth Environ Sci 2019, 331, 012029.

214. Li, Z. J.; Liu, M.; Dawuti, G.; Dou, Q.; Ma, Y.; Liu, H. G.; Aibai, S. Antifungal activity of gallic acid in vitro and in vivo. Phytother Res 2017, 31 (7), 1039-1045.

215. Kwun, M. S.; Lee, D. G. Quercetin-induced yeast apoptosis through mitochondrial dysfunction under the accumulation of magnesium in candida albicans. Fungal Biology 2020, 124 (2), 83-90.

216. Umayra, A. N.; Qasim, M. J.; Al-Yasari, A. K. S.; Dakheel, M. H. Immunological role of annona muricata (dietary supplement of gravula) against cypermethrin's toxic effects in female rats. Ann Trop Med Public Health 2020, 23, 103-109.

217. Kim, G.-T.; Tran, N. K. S.; Choi, E.-H.; Song, Y.-J.; Song, J.-H.; Shim, S.-M.; Park, T.-S. Immunomodulatory efficacy of standardized annona muricata (graviola) leaf extract via activation of mitogen-activated protein kinase pathways in raw 264.7 macrophages. Evid Based Complementary Altern Med 2016, 2905127.

218. Baser, K. H. Biological and pharmacological activities of carvacrol and carvacrol bearing essential oils. Curr Pharm Des 2008, 14 (29), 3106-3119.

219. Leyva-López, N.; Gutiérrez-Grijalva, E. P.; Vazquez-Olivo, G.; Heredia, J. B. Essential oils of oregano: Biological activity beyond their antimicrobial properties. Molecules 2017, 22 (6), 989.

220. Nostro, A.;Papalia, T. Antimicrobial activity of carvacrol: Current progress and future prospectives. Recent Pat Antiinfect Drug Discov 2012, 7 (1), 28-35.

221. Grbović, F.; Stanković, M. S.; Ćurčić, M.; Đorđević, N.; Šeklić, D.; Topuzović, M.; Marković, S. In vitro cytotoxic activity of origanum vulgare 1 . On hct-116 and mda-mb-231 cell lines. Plants 2013, 2 (3), 371-378.

222. Grevsen, K.; Fretté, X.;Christensen, L. P. Content and composition of volatile terpenes, flavonoids and phenolic acids in greek oregano (origanum vulgare 1. Ssp hirtum) at different development stages during cultivation in cool temperate climate. Europ J Horticult Sci 2009, 74, 193-203.

223. Oregano-PlantVillage. Available online: https://plantvillage.psu.edu/topics/oregano/infos/diseases_and_pests_description_uses propagation (Accessed on May 2021).

224. Gutiérrez-Grijalva, E. P.; Picos-Salas, M. A.; Leyva-López, N.; Criollo-Mendoza, M. S.; Vazquez-Olivo, G.; Heredia, J. B. Flavonoids and phenolic acids from oregano: Occurrence, biological activity and health benefits. Plants 2017, 7 (1), 2.

225. Elpiniki, S.; Alexandra, D. S.; Nicholaos, G. D. Ecology, cultivation and utilization of the aromatic greek oregano (origanum vulgare 1.): A review. Not Bot Horti Agrobot Cluj Napoca 2019, 47 (3), 545-552.

226. Guarda, A.; Rubilar, J. F.; Miltz, J.; Galotto, M. J. The antimicrobial activity of microencapsulated thymol and carvacrol. Int J Food Microbiol 2011, 146 (2), 144-150.

227. Sharifi-Rad, M.; Varoni, E. M.; Iriti, M.; Martorell, M.; Setzer, W. N.; Del Mar Contreras, M.; Salehi, B.; Soltani-Nejad, A.; Rajabi, S.; Tajbakhsh, M.; Sharifi-Rad, J. Carvacrol and human health: A comprehensive review. Phytother Res 2018, 32 (9), $1675-1687$.

228. Zhu, P.; Chen, Y.; Fang, J.; Wang, Z.; Xie, C.; Hou, B.; Chen, W.; Xu, F. Solubility and solution thermodynamics of thymol in six pure organic solvents. J ChemThermodyn 2016, 92, 198-206.

229. Ruiz Reyes, E.; Moreira Castro, J. Metabolitos secundarios en plantas medicinales usadas para problemas gastrointestinales. Una revisión sobre medicina ancestral ecuatoriana. Revista Bases de la Ciencia 2017, 2 (3), 1-16.

230. Pozzatti, P.; Scheid, L. A.; Spader, T. B.; Atayde, M. L.; Santurio, J. M.; Alves, S. H. In vitro activity of essential oils extracted from plants used as spices against fluconazole-resistant and fluconazole-susceptible candida spp. Can J Microbiol 2008, 54 (11), 950-956.

231. Food and Drug Administration. Available online: https://www.accessdata.fda.gov/scripts/cdrh/cfdocs/cfcfr/CFRSearch.cfm?fr=172.515\&SearchTerm=thymol (Accessed on March 2021).

232. Spyridopoulou, K.; Fitsiou, E.; Bouloukosta, E.; Tiptiri-Kourpeti, A.; Vamvakias, M.; Oreopoulou, A.; Papavassilopoulou, E.; Pappa, A.; Chlichlia, K. Extraction, chemical composition, and anticancer potential of origanum onites l. Essential oil. Molecules $2019,24(14), 2612$.

233. Coccimiglio, J.; Alipour, M.; Jiang, Z. H.; Gottardo, C.; Suntres, Z. Antioxidant, antibacterial, and cytotoxic activities of the ethanolic origanum vulgare extract and its major constituents. Oxid Med Cell Longev 2016, 1404505. 
234. Llana-Ruiz-Cabello, M.; Gutiérrez-Praena, D.; Pichardo, S.; Moreno, F. J.; Bermúdez, J. M.; Aucejo, S.; Cameán, A. M. Cytotoxicity and morphological effects induced by carvacrol and thymol on the human cell line caco-2. Food Chem Toxicol 2014, 64, 281290.

235. Potočnjak, I.; Gobin, I.; Domitrović, R. Carvacrol induces cytotoxicity in human cervical cancer cells but causes cisplatin resistance: Involvement of mek-erk activation. Phytother Res 2018, 32 (6), 1090-1097.

236. Zeng, Q.; Che, Y.; Zhang, Y.; Chen, M.; Guo, Q.; Zhang, W. J. D. D. Thymol isolated from thymus vulgaris 1. Inhibits colorectal cancer cell growth and metastasis by suppressing the wnt/ $\beta$-catenin pathway. Drug Des Devel Ther 2020, 14, 2535.

237. Khan, I.; Bahuguna, A.; Kumar, P.; Bajpai, V. K.; Kang, S. C. In vitro and in vivo antitumor potential of carvacrol nanoemulsion against human lung adenocarcinoma a549 cells via mitochondrial mediated apoptosis. Sci Rep 2018, 8 (1), 144.

238. Günes-Bayir, A.; Kocyigit, A.; Güler, E. M.; Bilgin, M. G.; Ergün İ, S.; Dadak, A. Effects of carvacrol on human fibroblast (ws1) and gastric adenocarcinoma (ags) cells in vitro and on wistar rats in vivo. Mol Cell Biochem 2018, 448 (1-2), $237-249$.

239. Gavaric, N.; Mozina, S. S.; Kladar, N.; Bozin, B. Chemical profile, antioxidant and antibacterial activity of thyme and oregano essential oils, thymol and carvacrol and their possible synergism. J Essent Oil-Bear Plants 2015, 18 (4), $1013-1021$.

240. Llana-Ruiz-Cabello, M.; Gutiérrez-Praena, D.; Puerto, M.; Pichardo, S.; Jos, Á.; Cameán, A. M. In vitro pro-oxidant/antioxidant role of carvacrol, thymol and their mixture in the intestinal caco-2 cell line. Toxicol In Vitro 2015, 29 (4), 647-656.

241. Sharifi-Rad, J.; Salehi, B.; Schnitzler, P.; Ayatollahi, S. A.; Kobarfard, F.; Fathi, M.; Eisazadeh, M.; Sharifi-Rad, M. Susceptibility of herpes simplex virus type 1 to monoterpenes thymol, carvacrol, p-cymene and essential oils of sinapis arvensis 1. , lallemantia royleana benth. And pulicaria vulgaris gaertn. Cell Mol Biol 2017, 63 (8), 42-47.

242. Sánchez, G.;Aznar, R. Evaluation of natural compounds of plant origin for inactivation of enteric viruses. Food Environ Virol 2015, 7(2), 183-187.

243. Han, X.;Parker, T. L. Anti-inflammatory, tissue remodeling, immunomodulatory, and anticancer activities of oregano (origanum vulgare) essential oil in a human skin disease model. Biochim Open 2017, 4, 73-77.

244. Wu, H.; Jiang, K.; Yin, N.; Ma, X.; Zhao, G.; Qiu, C.; Deng, G. Thymol mitigates lipopolysaccharide-induced endometritis by regulating the tlr4- and ros-mediated nf-kb signaling pathways. Oncotarget 2017, 8 (12), 20042-20055.

245. Zarrini, G.; Delgosha, Z. B.; Moghaddam, K. M.; Shahverdi, A. R. Post-antibacterial effect of thymol. Pharm Biol 2010, 48 (6), 633-636.

246. Gniewosz, M.; Synowiec, A. Antibacterial activity of pullulan films containing thymol. Flavour Frag J 2011, 26 (6), $389-395$.

247. Du, E.; Gan, L.; Li, Z.; Wang, W.; Liu, D.; Guo, Y. In vitro antibacterial activity of thymol and carvacrol and their effects on broiler chickens challenged with clostridium perfringens. J Anim Sci Biotechnol 2015, 6, 58.

248. Lu, M.; Dai, T.; Murray, C. K.;Wu, M. X. Bactericidal property of oregano oil against multidrug-resistant clinical isolates. Front Microbiol 2018, 9, 2329.

249. Magi, G.; Marini, E.; Facinelli, B. Antimicrobial activity of essential oils and carvacrol, and synergy of carvacrol and erythromycin, against clinical, erythromycin-resistant group a streptococci. Front Microbiol 2015, 6, 165.

250. Numpaque, M. A.; Oviedo, L. A.; Gil, J. H.; García, C. M.; Durango, D. L. Thymol and carvacrol: Biotransformation and antifungal activity against the plant pathogenic fungi colletotrichum acutatum and botryodiplodia theobromae. Trop Plant Pathol 2011, 36 (1), 3-13.

251. Pérez-Alfonso, C. O.; Martínez-Romero, D.; Zapata, P. J.; Serrano, M.; Valero, D.; Castillo, S. The effects of essential oils carvacrol and thymol on growth of penicillium digitatum and p. Italicum involved in lemon decay. Int J Food Microbiol 2012, 158 (2), 101-106.

252. Abbaszadeh, S.; Sharifzadeh, A.; Shokri, H.; Khosravi, A. R.; Abbaszadeh, A. Antifungal efficacy of thymol, carvacrol, eugenol and menthol as alternative agents to control the growth of food-relevant fungi. J Mycol Med 2014, 24 (2), e51-e56.

253. Suwanamornlert, P.; Sangchote, S.; Chinsirikul, W.; Sane, A.; Chonhenchob, V. Antifungal activity of plant-derived compounds and their synergism against major postharvest pathogens of longan fruit in vitro. Int J Food Microbiol 2018, $271,8-14$.

254. Ochoa-Velasco, C. E.; Navarro-Cruz, A. R.; Vera-López, O.; Palou, E.; Avila-Sosa, R. Growth modeling to control (in vitro) fusarium verticillioides and rhizopus stolonifer with thymol and carvacrol. Rev Argent Microbiol 2018, 50 (1), $70-74$.

255. Shu, C.; Sun, L.; Zhang, W. Thymol has antifungal activity against candida albicans during infection and maintains the innate immune response required for function of the p38 mapk signaling pathway in caenorhabditis elegans. Immunol Res 2016, 64 (4), 1013-1024.

256. De Santis, F.; Poerio, N.; Gismondi, A.; Nanni, V.; Di Marco, G.; Nisini, R.; Thaller, M. C.; Canini, A.; Fraziano, M. Hydroalcoholic extract from origanum vulgare induces a combined anti-mycobacterial and anti-inflammatory response in innate immune cells. PLoS One 2019, 14 (3), e0213150.

257. Gholijani, N.; Amirghofran, Z. Effects of thymol and carvacrol on t-helper cell subset cytokines and their main transcription factors in ovalbumin-immunized mice. J Immunotoxicol 2016, 13 (5), 729-737.

258. Tisserand, R.; Young, R., 14 - constituent profiles. In Essential oil safety (second edition), Tisserand, R.; Young, R., Eds. Churchill Livingstone: St. Louis, 2014; 483-647.

259. Ris, M. M.; Deitrich, R. A.; Von Wartburg, J. P. Inhibition of aldehyde reductase isoenzymes in human and rat brain. Biochem Pharmacol 1975, 24 (20), 1865-1869.

260. Tinworth, C.P.; Young, R.J. Facts, Patterns, and Principles in Drug Discovery: Appraising the Rule of 5 with Measured Physicochemical Data. J Med Chem 2020, 63, 10091-10108.

261. Pollastri, M.P. Overview on the Rule of Five. Current Protocols in Pharmacology 2010, Chapter 9, Unit 9.12.

262. Benet, L.Z.; Hosey, C.M.; Ursu, O.; Oprea, T.I. BDDCS, the Rule of 5 and drugability. Adv Drug Deliv Rev 2016, 101, 89-98. 
